\title{
Analysis of sialyl-Lewis $x$ on MUC5AC and MUC1 mucins in pancreatic cancer tissues.
}

Meritxell Balmaña $^{1,2}$, Adrià Duran ${ }^{1}$, Catarina Gomes ${ }^{2}$, Esther Llop ${ }^{1}$, Raquel López-Martos ${ }^{5}$, M. Rosa

Ortiz $^{5}$, Sílvia Barrabés ${ }^{1}$, Celso A. Reis ${ }^{2,3,4 \#}$, Rosa Peracaula ${ }^{1 \#}$

${ }^{1}$ Biochemistry and Molecular Biology Unit, Department of Biology, University of Girona, Girona, Spain.

${ }^{2}$ Instituto de Investigação e Inovação em Saúde, I3S; and Institute of Molecular Pathology and Immunology of University of Porto, Ipatimup; Porto, Portugal.

${ }^{3}$ Medical Faculty, University of Porto, Al. Prof. Hernâni Monteiro, 4200 - 319 Porto, Portugal ${ }^{4}$ Instituto de Ciências Biomédicas de Abel Salazar - ICBAS, University of Porto, Porto, Portugal ${ }^{5}$ Department of Anatomic Pathology, Dr. Trueta University Hospital, Girona, Spain.

\#Correspondence should be addressed to Celso A. Reis, IPATIMUP/i3S, Rua Alfredo Allen, 208 4200-135 Porto - Portugal, E-mail: celsor@ipatimup.pt. Tel: +351 220408800; Fax: 351225570799 or Rosa Peracaula, Biochemistry and Molecular Biology Unit, Department of Biology, University of Girona, 17071 Girona, Spain. E-mail: rosa.peracaula@udg.edu. Tel:+34 972418370; Fax: +34 972418150 . 


\begin{abstract}
Pancreatic adenocarcinoma (PDAC) lacks efficient biomarkers. Mucins are glycoproteins that can carry aberrant glycosylation in cancer. Our objective was to identify cancer-related glycan epitopes on MUC1 and MUC5AC mucins in PDAC as potential biomarkers. We have analysed the tumourassociated carbohydrate antigens sialyl-Lewis $\mathrm{x}\left(\mathrm{SLe}^{\mathrm{x}}\right)$ and sialyl-Tn (STn) on MUC1 and MUC5AC in PDAC tissues. The selected cohort for this study consisted of twenty-one PDAC tissues positive for SLe $^{\mathrm{x}}$ antigen and three normal pancreas specimens as controls. STn expression was shown in $76 \%$ of the PDAC tissues. MUC1 and MUC5AC were detected in 90\% of PDAC tissues. We performed in situ proximity ligation assay combining antibodies against mucins and glycan epitopes to identify specific mucin glycoforms. MUC1-SLe ${ }^{\mathrm{x}}$ and MUC5AC-SLe ${ }^{\mathrm{x}}$ were found in $68 \%$ and $84 \%$ respectively, of the mucin expressing PDAC tissues, while STn hardly colocalized with any of the evaluated mucins. Further analysis by Western blot of MUC5AC and SLe ${ }^{\mathrm{x}}$ in eight PDAC tissue lysates showed that six out of eight cases were positive for both markers. Moreover, immunoprecipitation of MUC5AC from positive PDAC tissues and subsequent SLe ${ }^{\mathrm{x}}$ immunodetection confirmed the presence of SLe ${ }^{\mathrm{x}}$ on MUC5AC. Altogether, MUC5AC-SLe ${ }^{\mathrm{x}}$ glycoform is present in PDAC and can be regarded as potential biomarker.
\end{abstract}

Keywords: mucins; pancreatic cancer; sialyl-Lewis x.

Abbreviations: PDAC, pancreatic cancer; PLA, in situ proximity ligation assay; SLe ${ }^{\mathrm{x}}$, sialyl-Lewis x; STn, sialyl-Tn 


\section{Introduction}

Pancreatic adenocarcinoma (PDAC) is estimated to be the third leading cause of cancer death in the United States [1] and is projected to become the second cause of cancer-related death by 2030 [2]. PDAC is one of the cancers with the lowest survival rate ( $7 \%$ in 5 years), due to a late diagnosis and the intrinsic aggressiveness of this tumour [3]. Unfortunately, and in contrast to the declining trends for most cancers, PDAC is one of the few neoplasms with increasing incidence and mortality in both genders $[1,4]$.

Despite the efforts made in the last decades to discover new biomarkers, there is still a lack of biomarkers with enough specificity and sensitivity. This reduces the chances of detection of PDAC in early stages, when curative procedures are most effective [5]. For the majority of patients the only available treatment is the administration of gemcitabine, a chemotherapeutic agent that has shown beneficial effects in only $20-30 \%$ of patients $[6,7]$.

Mucins are high molecular weight glycoproteins expressed on epithelial cells. A multitude of oligosaccharides are attached to the polypeptide backbone of mucins which can be bound to the cell membrane or secreted into the organ lumen. Mucins constitute a selective barrier and play an important role in cell adhesion, immune response, cell signalling and in the renewal and differentiation of the epithelium [8-10]. Mucin expression and their glycosylation are altered in many tumours [11, 12], including breast [13], colon [14, 15], gastric [16-18], lung [19], and PDAC [20, 21]. These alterations influence cellular growth, differentiation, malignant transformation, adhesion, invasion and immune surveillance $[8,11,22,23]$.

MUC1 is a membrane-bound mucin that contains a variable number of tandem repeats (VNTR), between 20 and 125, which are abundantly $O$-glycosylated. Its molecular mass is therefore variable ranging from $120-225 \mathrm{kDa}$ (protein backbone) and significantly larger when glycosylated, up to 500 kDa. MUC1 can also be secreted after cleavage of its extracellular domain. It is expressed at the apical surface of ductal epithelia of tissues, including breast, pancreas, bronchus and the gastrointestinal tract $[17,24,25]$. In normal pancreas, the common staining of MUC1 is at the cytoplasmic level in acinar cells and in the apical area of ductal cells [26], and it is well-established that MUC1 is overexpressed in malignant situation $[26,27]$. MUC5AC is a secreted mucin of a polypeptide chain of approximately 
$586 \mathrm{kDa}$, but with a much higher molecular weight especially due to the large number of $O$ -

glycosylated chains attached to Ser and Thr residues in the VNTR regions. It is only expressed in 2$4 \%$ of healthy pancreas [6]. Regarding PDAC, MUC5AC has been shown to be expressed in the cytoplasm and is de novo expressed in around 75-92\% of the PDAC cases [27-29] and is also detected in $70 \%$ of PanIN1A cases, which is the earliest stage of the most common precursor lesions of PDAC [27].

Aberrant glycosylation of cell surface glycolipids, membrane associated glycoproteins and secreted glycoproteins is a universal feature of malignant transformation [23, 30-32]. For instance, in malignant pancreatic tissues the carbohydrate antigens sialyl-Lewis $\mathrm{x}\left(\mathrm{SLe}^{\mathrm{x}}\right)$ and sialyl Tn $(\mathrm{STn})$ have been described to be commonly expressed over $80 \%[33,34]$ and $77 \%$ [27] respectively, while they are not detected in healthy pancreatic specimens $[33,35]$. Moreover, SLe ${ }^{\mathrm{x}}$ and $\mathrm{STn}$ expression have been associated with tumour progression and metastasis $[36,37] . \mathrm{STn}$ is an $O$-linked disaccharide which consists of an $\alpha 2,6$-linked $\mathrm{N}$-acetylneuraminic acid attached to $\mathrm{N}$-acetylgalactosamine and is often aberrantly expressed in the neoplastic lesions including PDAC [32]. SLe ${ }^{\mathrm{x}}$ epitope is a terminal structure ( $\mathrm{N}$-acetylneuraminic acid $\alpha 2,3$-Galactose $\beta 1,4[$ Fucose $\alpha 1,3] \mathrm{N}$-acetylglucosamine) that can be found in either $N$ - or $O$-glycosylated molecules [32, 38].

Mucins are known to be major carriers of tumour associated carbohydrate antigens and, since they are overexpressed in adenocarcinomas, these glycan alterations are highly amplified on the surface of tumour cells [12]. In gastric tissues, a recent study that characterizes mucin $O$-glycosylation, reports the presence of sialylated glycans, including sialyl-Lewis antigens. A higher level of sialylation and sulfation on gastric $O$-glycans were found in cancerous tissue compared to healthy tissue [18]. In colon cancer, an increase expression of a core 3 sialyl-Le ${ }^{x}$ hexasaccharide, which appeared to compete with its sulfo-Le ${ }^{\mathrm{x}}$ counterpart in normal tissue, was described on MUC2, suggesting its use as a potential marker of malignant transformation [15]. Therefore, the detection of the cancer related glycosylation on mucins could give rise to more specific and /or sensitive cancer diagnostic markers. The expression of STn antigen on MUC1 and MUC5AC has been previously described in stomach, colon, lung, breast and ovarian tumours [39]. Recently, Remmers and coauthors have shown the expression of Tn/STn on MUC1 in PDAC tissues (91\%) using an antibody directed to Tn/STn MUC1 


\section{Materials and methods}

\subsection{Human tissue samples}

Pancreatic tissues were obtained from the Hospital Dr. Josep Trueta (Girona, Spain) from patients undergoing surgical resection following the standard operating procedures of its Ethics Committee. Normal pancreatic tissue refers to adjacent, non-tumour pancreatic tissue from patients with pancreatic-related disorders. The histopathologic features of the resected specimens were confirmed by biopsy or image examination by the Digestive and Pathology Units and classified according to the Tumour Node Metastasis Classification of Malignant Tumours of the International Union Against Cancer (UICC) 7th edition [46]. For immunohistochemistry and PLA, 21 PDAC and three normal tissues were used. PDAC tissues were from 15 males and 6 females, ranging 49-81 years old; six were stage IIA ( 1 well differentiated, 4 moderately differentiated and one poorly differentiated), thirteen stage IIB (five well differentiated, six moderately differentiated and two poorly differentiated), one stage II* (unclassified A or B due to the lack of available information of the nodule affectation, 
moderately differentiated), and one stage IV (well differentiated). Tissues were fixed in $10 \%$ formalin, embedded in paraffin and cut into $5 \mu \mathrm{m}$ serial sections for immunohistochemistry (IHC) and in situ Proximity Ligation Assays (PLAs). Hematoxilin eosin staining of the tissues was performed in the same tissue blocks but not in the consecutive serial slides of the IHC and PLA assays. For protein lysates, eight PDAC and four normal tissues were used. PDAC tissues were from seven males and one female; ranging 59-79 years old. Six tissues were stage IIB and two stage IV. A small piece of each tissue was immediately frozen in liquid nitrogen and kept at $-80^{\circ} \mathrm{C}$ until their use.

\subsection{Immunohistochemistry}

Paraffin sections were dewaxed and rehydrated. Endogenous peroxidase activity was blocked with 3\% $\mathrm{H}_{2} \mathrm{O}_{2}$ in methanol for 10 min, and then sections were incubated with normal rabbit serum diluted $1 / 5$ in PBS containing 10\% BSA. Normal serum excess was removed and replaced by specific primary antibody in the appropriate concentration (Table 1) in PBS with 5\% BSA and incubate overnight at 4 ${ }^{\circ} \mathrm{C}$. Slides were then washed in PBS and incubated for 30 min with secondary biotinylated rabbit antimouse antibody (Dako, Glostrup, Denmark) diluted 1/200 in PBS containing 5\% of BSA. The slides were subsequently washed in PBS and incubated for $30 \mathrm{~min}$ with avidin-biotin complex (Vectastain Elite ABC kit, Burlingame, CA) according to the manufacturer's recommendations. Staining was performed with 3,3-diaminobenzidine tetrahydrochloride (Sigma, St. Louis, MO) containing 0.02\% hydrogen peroxide. Counterstaining of the nucleus was done with Mayer's hematoxylin solution. Slides were examined under a bright-field microscope AH2 Vanox-T microscope Olympus. Images were acquired using an Olympus microscope digital camera DP73 and the CellSens Standard 1.11 software.

SLe ${ }^{\mathrm{x}}$ and MUC1-M8 immunostainings were performed using the KM93 and M8 monoclonal detection antibodies, and a biotinylated goat anti-mouse $\operatorname{IgM}$ at $1 / 200$ and a biotinylated horse anti-IgG at 1/100 antibodies (Vectastain Elite ABC kit) in $1.5 \%$ of goat serum or $1.5 \%$ of horse serum, respectively in PBS, following the protocol described in [47]. CSLEX antibody (at 1/20 dilution) (BD Biosciences, San Jose, CA) was used to compare the SLex immunostaining obtained with the KM93 antibody. 
Staining intensity was graded to the frequency of positive cells as: strongly positive ( $>60 \%$ stained cells), moderately positive ( $25-60 \%$ stained cells), faintly positive ( $<25 \%$ stained cells), sparse cells and negative. The histological analysis and scoring of the tissues were performed by two independent expert pathologists of the Hospital Dr. Josep Trueta of Girona.

\subsection{Purification and quantification of monoclonal antibodies}

VU4H5 (MAb anti-MUC1), CLH2 (MAb anti-MUC5AC) and TKH2 (MAb anti-STn) were purified with HiTrap Protein G sepharose columns (GE Healthcare, Amersham Biosciences, Üppsala, Sweden), according to the manufacturer's protocol. Desorption buffer was exchanged into phosphate buffer saline (PBS, pH 7.4) using Amicon Ultra-0.5 10K Centrifugal Filters (Millipore, Billerica, MA).

\subsection{In situ Proximity Ligation Assay}

In situ Proximity Ligation Assay (PLA) was performed in paraffin sections from controls and PDAC cases for colocalization analysis of SLe ${ }^{\mathrm{x}}$ and STn antigens with the MUC1 and MUC5AC mucins. Firstly, Duolink In Situ Probemaker kit (Sigma-Aldrich, St. Louis, MO) was used to conjugate the PLA oligonucleotide arms directly to the purified primary antibodies. TKH2 (anti-STn) was conjugated with the MINUS probes (Olink DUO920010, Olink Bioscience, Uppsala, Sweden), and VU4H5 (anti-MUC1) and CLH2 (anti-MUC5AC) with the PLUS probes (Olink DUO92009) according to the manufacturer's instructions. KM93 (MAb anti-SLe ${ }^{\mathrm{x}}$ ) antibody was not labelled with PLA probe due to its IgM nature. Thus, the secondary antibodies AffiniPure goat anti-mouse IgG (subclass 1) and AffiniPure goat anti-mouse IgM (both from Jackson ImmunoResearch, West Grove, PA) were labelled using the previously detailed oligonucleotides Olink DUO920010 and Olink DUO92009, respectively.

Deparaffined tissue sections were pre-treated according to the immunohistochemistry protocol explained above. Then, sections were incubated for $30 \mathrm{~min}$ at $37^{\circ} \mathrm{C}$ with the Blocking Solution (Duolink In Situ Probemaker kit). For colocalization of mucins with STn epitope, primary antibodies conjugated with oligoprobes were used. Conjugated MAbs to MUC1 (1/40) or MUC5AC (1/100) and 
STn (1/40) were diluted in PBS with 5\% BSA containing 1/20 of assay reagent (Duolink In Situ

Probemaker kit) and slides were incubated overnight at $4{ }^{\circ} \mathrm{C}$. Slides were then washed with a filtered solution of $0.01 \mathrm{M}$ Tris, $0.15 \mathrm{M} \mathrm{NaCl}$ and $0.05 \%$ Tween 20 (Wash buffer A) prior to the ligation step. The ligation solution was prepared diluting the two oligonucleotides $1 / 5$ and the ligase $1 / 40$ (Duolink In Situ Detection Reagents Orange, Sigma-Aldrich) in pure water, and was added to slides and incubated for 30 minutes at $37^{\circ} \mathrm{C}$ in order to hybridize with the PLA probes and to form a closed circle. After a wash with buffer A, the amplification was performed in darkness adding the amplification solution to the samples, consisting of nucleotides and fluorescently labelled oligonucleotides, together with the polymerase both diluted in pure water $1 / 5$ and $1 / 80$, respectively. The slides were washed with $0.2 \mathrm{M}$ Tris and $0.1 \mathrm{M} \mathrm{NaCl}$ (Wash buffer $\mathrm{B}$ ) and then were incubated with DAPI to visualise nuclei (Sigma-Aldrich, $0.4 \mathrm{mg} / \mathrm{mL}$ ). After washing slides with $0.01 \mathrm{x}$ wash buffer B, samples were mounted with Vectashield Mounting Medium (Vector Laboratories, Burlingame, CA). All slides were examined under a Zeiss Imager.Z1 Axio fluorescence microscope (Zeiss, Welwyn Garden City, UK). Images were acquired using a Zeiss Axio cam MRm and the AxioVision Release 4.8.1 software.

The analyses of the colocalization of MUC1 and MUC5AC with SLe ${ }^{\mathrm{x}}$ epitope were performed using secondary antibodies with oligoprobes. The procedure was similar to as previously described for the PLA with incubations of VU4H5, CLH2 (both IgGs subtypes) and KM93 (IgM subtype) primary antibodies (same conditions as for the immunohistochemistry) followed by $1 \mathrm{~h}$ incubation at $37^{\circ} \mathrm{C}$ with the goat anti-mouse IgG1 and goat anti-mouse IgM oligoprobe secondary antibodies, diluted 1/300. Imaging analysis of the PLA signal was performed with the Duolink Image Tool software (SigmaAldrich). These quantifications were performed for the imaging analysis of the PLA results of SLe MUC1 and SLe $\mathrm{x}-\mathrm{MUC5}$ AC colocalization for each of the tissues. Briefly, several representative images per case were subjected to the software analysis and the median of positive blobs (positive PLA events) was set up for each case. Then, the median of positivity for each PLA combination was determined and 3 categories were established as follows: +++ (positive cases whose median is higher than $75 \%$ of the overall median); ++ (positive cases higher than $25 \%$ and lower than $75 \%$ ); and + (positive cases lower than 25\%). 


\subsection{Tissue protein lysate}

Frozen PDAC and normal pancreatic tissues were thawed, mixed with RIPA buffer [(20 mM sodium phosphate, $150 \mathrm{mM} \mathrm{NaCl}, 5 \mathrm{mM}$ EDTA, 1\% (v/v) Triton X-100 (pH 7.4,)] supplemented with a protease inhibitor cocktail Complete Ultra tablets (Roche, Basel, Switzerland), and homogenised with lysing matrix beads D in a FastPrep-24 Instrument (MP Biomedicals, Santa Ana, CA). Tissue homogenates were centrifuged $5 \mathrm{~min}$ at $14000 \mathrm{~g}$ at $4{ }^{\circ} \mathrm{C}$. The supernatant was collected and total protein quantified with bicinchoninic acid assay (BCA) (Thermo Scientific Pierce, Waltham, MA).

\subsection{Immunoprecipitation}

For immunoprecipitation assays, cell lysates containing equal amounts of protein $(500 \mu \mathrm{g})$ were reduced in buffer containing dithiothreitol such that the final concentration when mixed with sample was $10 \mathrm{mM}$. After $2 \mathrm{~h}$ incubation at $37^{\circ} \mathrm{C}$, fresh iodoacetamide was added to a final concentration of $25 \mathrm{mM}$ and samples were incubated at room temperature for 30 minutes in the dark.

After reduction and alkylation, samples were desalted and concentrated using Amicon Ultra-0.5 3kDa Centrifugal Filter Devices (Millipore) which had been previously passivated with 5\% Brij-35 (Sigma). Next, samples were diluted in incubation buffer, $50 \mathrm{mM}$ Tris $\mathrm{pH}$ 7.4, $150 \mathrm{mM} \mathrm{NaCl}$ and $1 \%$ Triton X100, 5mM EDTA and protease inhibitors (complete ultratablets from Roche), and precleared with 100 $\mu \mathrm{L}$ of Protein $\mathrm{G}$ agarose resin for two hours at $4{ }^{\circ} \mathrm{C}$. The precleared samples were incubated with 20 $\mu \mathrm{L}$ of anti-MUC5AC polyclonal antibody (Lum5.1) for two hours at $4{ }^{\circ} \mathrm{C}$. The immunocomplexes were then captured by incubating samples with Protein G agarose resin packed into a spin column (Corning Costar Spin-X, New York, NY) overnight at $4{ }^{\circ} \mathrm{C}$. Protein G column were centrifuged and washed three times with washing buffer (50 mM Tris $\mathrm{pH} 7.4,150 \mathrm{mM} \mathrm{NaCl}$ and 1\% Triton X-100). MUC5AC bound to the Lum5.1 antibody was eluted after boiling the sample with Laemmli buffer containing $1.25 \% \beta$-mercaptoethanol.

\subsection{Western Blot}


Twenty micrograms of each protein lysate or immunoprecipitated MUC5AC from tissues were prepared on Laemmli sample buffer containing $1.25 \% \beta$-mercaptoethanol and heated at $95^{\circ} \mathrm{C}$ for 5 min. Samples were then loaded in duplicate and separated with a 3\% stacking 5\% resolving gel and transferred to a PVDF membrane for $4 \mathrm{~h}$ at $100 \mathrm{~V}$ in Towbin buffer (25 mM Tris, $192 \mathrm{mM}$ glycine, $20 \% \mathrm{v} / \mathrm{v}$ methanol, $\mathrm{pH} 8.3$ ) containing $0.1 \% \mathrm{SDS}$ to promote transfer of high molecular weight proteins. Afterwards, membranes were blocked with 3\% BSA in TBST $(10 \mathrm{mM}$ Tris, $100 \mathrm{mM} \mathrm{NaCl}$, $0.05 \% \mathrm{v} / \mathrm{v}$ Tween-20, $\mathrm{pH} 7.4$ ) overnight at RT with shaking.

Membranes were washed, cut in two separated pieces, one was incubated with anti-MUC5AC (Lum5.1) diluted 1/1.000 in 3\% BSA in TBST and the other one with anti-sLe ${ }^{\mathrm{x}}$ monoclonal antibody (Clone KM93) diluted 1/60 in 0.5\% BSA in TBST for two hours (Table 1). Next, the former membrane was washed and incubated with a goat horseradish peroxidase-conjugated anti-rabbit antibody (Pierce Biotechnology, Rockford, IL) and the latter was incubated with a goat F(ab')2 antimouse IgG $+\operatorname{IgM}+\operatorname{IgA}$ horseradish peroxidase-conjugated antibody (Abcam, Cambridge, UK) diluted $1 / 40.000$ in $0.5 \%$ BSA in TBST for one hour. After washing, membranes were incubated for $5 \mathrm{~min}$ with Immobilon Western horseradish peroxidase substrate solution (Millipore, Billerica, MA). Chemiluminescence was visualized using the imaging system Fluorochem SP (AlphaInnotech, San Leandro, CA) under non-saturating conditions.

Western Blots with anti-STn, diluted in 0,5\% BSA in TBST, anti-MUC1 antibody (M8, Table 1) diluted 1/10 in 3\% BSA in TBST and anti-vinculin antibody (Santa Cruz Biotechnology, Dallas TX) diluted $1 / 200$ in $0.5 \%$ skimmed milk in TBST were performed as described above using a goat $\mathrm{F}\left(\mathrm{ab}^{\prime}\right) 2$ anti-mouse IgG+IgM+IgA horseradish peroxidase-conjugated antibody (Abcam) for STn and MUC1 detection and horseradish peroxidase-conjugated mouse IgG $\kappa$ light chain binding protein diluted $1 / 5000$ in $0.5 \%$ skimmed milk in TBST for vinculin detection (Santa Cruz Biotechnology).

\section{Results}

\subsection{Expression of sialylated glycan epitopes (SLe ${ }^{x}$ and STn) in pancreatic tissues}

First, we analysed the presence of the carbohydrate antigens SLe ${ }^{\mathrm{x}}$ and STn by immunohistochemistry. Positive SLe ${ }^{\mathrm{x}}$ staining was the criteria to select the cohort of PDAC tissues of this work. From our 
initial cohort of 25 PDAC tissues, 21 were SLe ${ }^{\mathrm{x}}$ positive corresponding to $84 \%$ of the total samples, which is in agreement with the literature $[33,34]$. Since several studies have described SLe expression using CSLEX antibody, we compared the immunostaining pattern of the antibody KM93 with that of CSLEX on four PDAC tissues and a control tissue. Both antibodies showed the same staining pattern in the luminal and cytoplasmatic areas of ductal cancer cells from the four PDAC tissues and no staining was detected in the control tissue (Fig.S1). From the $21 \mathrm{SLe}^{\mathrm{x}}$ positive tissues, 16 were also positive for STn and two were STn positive staining in few sparse cells (Tables 2 and 3). The 21 selected tissues were analysed for mucin expression and PLA experiments. As expected, both tumour-associated carbohydrate antigens were not expressed in normal pancreas tissues (Fig.1).

\subsection{Expression of MUC1 and MUC5AC in pancreatic tissues}

The immunohistochemical analysis with VU4H5 antibody showed MUC1 expression in normal and in most of the PDAC tissues (Tables 3 and 4). To our knowledge, this is the first time that the VU4H5, which is specific against APDTRPAP in the hypoglycosylated VNTR region of MUC1, has been tested in pancreatic tissues. In normal pancreas, MUC1 was stained in the acinar cells and faintly in some duct cells (Fig. 2A-C), as previously described [20]. Most PDAC tissues (Fig. 2D-I) were positively stained, however two cases stained only in few sparse cells. These two samples were then assessed using M8 antibody (anti-MUC1, Table 1), which targets the DTR within the VNTR extracellular domain [48] and it was observed higher positivity in tumour cells when compared withVU4H5 staining (data not shown). VU4H5 recognises the non-glycosylated APDTRPAP epitope whereas M8 antibody also recognises this epitope when it is glycosylated [49] and this can explain the increase in MUC1 positivity when using the M8 antibody. PDAC cells from well to poor differentiated tumours presented cytoplasmic staining with more intense membranous staining when compared to controls. MUC1 was also detected in secretions.

MUC5AC is a mucin which is neo-expressed in pancreas under malignant conditions. The expression of this mucin in the three controls were negative (Fig. 2J-L) while $90 \%$ of the PDAC samples were positively stained (Fig. 2M-R). MUC5AC staining was localized in the mucus and in some cases within the secretory compartments of ductal cells of cancer tissues. This indicates that epithelial cells 

sequence of the MUC5AC independently of glycosylation.

\subsection{Expression of sialylated antigens on MUC1 and MUC5AC in PDAC tissues.}

In situ PLA is a technique based on the detection of two epitopes located in close proximity employing oligonucleotide-conjugated antibodies (PLA probes). When two antigens are in close proximity, a bridging sequence links the two oligonucleotide sequences present in the different antibodies and a template for a rolling circle amplification is formed. Fluorescently labelled oligonucleotides hybridise with the product of the amplification generating easily detected fluorescent signal [50].

All tissues of the cohort including control and negative samples (with negative staining for at least one of the four antigens analysed) were PLA tested. All healthy tissues presented negative PLA results since it was not possible to detect SLe ${ }^{\mathrm{x}}$ or STn by IHC.

In situ PLA showed colocalization of SLe ${ }^{\mathrm{x}}$ with MUC1 in $68 \%$ of the PDAC tissues that were individually positive for both antigens (Table 5, Fig. 3A-F). Staining intensity results for each of the tissues examined by PLA and subjected to subsequent imaging analysis are shown in Table 6 . The colocalization was detected in the apical area of the well and moderately differentiated PDAC ducts and in the secreted mucus (Fig. 3C). Moreover, MUC1 bearing SLe ${ }^{\mathrm{x}}$ could be detected in the tumour cells of poorly differentiate tissues (Fig. 3F). Among the positive tissues for MUC1-SLe ${ }^{\mathrm{x}}$ colocalization, about one third of the tissues were faintly positive.

Regarding MUC5AC-SLe ${ }^{x}$ PLA, 16 out of 19 PDAC tissues (84\%) that expressed individually both MUC5AC and SLe ${ }^{\mathrm{x}}$ were MUC5AC-SLe ${ }^{\mathrm{x}}$ positive (Tables 5 and 6, Fig. 4A-I). Regarding the 3 negative tissues for MUC5AC-SLe ${ }^{\mathrm{x}}, 2$ of them were faintly positive $(<25 \%)$ and one moderately positive (25-60\%) for MUC5AC by immunohistochemistry. The colocalization was also found in the apical area of the well and moderately differentiated PDAC ducts (Fig. 4C), in the secreted mucus (Fig. 4F) and in the tumour cells of poorly differentiated tumours (Fig. 4I). The faintly positive tissues for MUC5AC-SLe ${ }^{\mathrm{x}}$ represented 19\% (3/16) of the positive cases.

The study of the colocalization of the mucins MUC1 and MUC5AC with the STn antigen showed only four marginally positive cases for MUC1-STn (Table 5, Fig. 5C) and two positive samples presented 
some isolated fluorescent dots in the mucus for MUC5AC-STn (Table 5, Fig. 5F). The tissues

included in this work were mostly stage IIA and IIB. None of the IIA cases presented colocalization for STn with MUC1 or MUC5AC.

\subsection{Determination of MUC5AC-SLe ${ }^{x}$ glycoform in pancreatic cancer tissues by immunoprecipitation followed by Western blot.}

The expression pattern of $\mathrm{SLe}^{\mathrm{x}}$ on MUC5AC, which showed the most promising results by PLA in this work, was further examined by a different approach. Western blot analyses of twenty micrograms of protein lysates from pancreatic adenocarcinoma and control pancreatic tissues were performed in duplicate in the same gel using Lum5.1 (anti-MUC5AC) and KM93 (anti-SLe ${ }^{\mathrm{x}}$ ) antibodies. MUC5AC and $\mathrm{SLe}^{\mathrm{x}}$ were absent in normal pancreas $(4 / 4)$, while $75 \%$ of the PDAC tissues ( 6 out of 8 ) presented a high molecular weight reactive band corresponding to MUC5AC (Fig. 6A). All tissues that were positive for MUC5AC showed also positive staining for SLe ${ }^{\mathrm{x}}$ at the same molecular weight.

Remarkably, similar expression levels and band pattern for MUC5AC and SLe ${ }^{\mathrm{x}}$ were observed in each positive sample. The presence of vinculin, a constitutively expressed protein, of MUC1 and STn were also analysed by Western Blot on 20 micrograms of the protein lysates (Fig. S2). Vinculin expression was found similar among the samples. MUC1 was expressed in the normal pancreas and in most of the pancreatic cancer tissues and STn was not found in the control tissue and was expressed in some of the tumour tissues at different levels, which was in accordance with the IHC results. These results show that the differences found in mucins and carbohydrate antigen expression were intrinsic of each PDAC sample and not due to differences in the amount of total protein. Hence, suggesting that MUC5AC could be a major carrier of SLe ${ }^{\mathrm{x}}$ in PDAC tissues.

In order to validate that MUC5AC was bearing the SLe ${ }^{\mathrm{x}}$ epitope, a MUC5AC immunoprecipitation protocol from PDAC tissues was set up. Gel-forming mucins have an oligomeric structure stabilized by disulphide bonds and can be depolymerized by treatment with a reducing agent. Therefore, considering the complex nature of MUC5AC, reduction and alkylation of the lysed samples were performed to facilitate the immunocapture of MUC5AC. Although CLH2 and Lum5.1 anti-MUC5AC 
antibodies were both assessed for immunoprecipitation, only the latter worked properly with our immunoprecipitation protocol (described in section 2.6). After sample immunoprecipitation of selected PDAC tissues, which expressed individually both MUC5AC and SLe ${ }^{\mathrm{x}}$, a high molecular weight band above $250 \mathrm{kDa}$ corresponding to MUC5AC was detected. Western blotting of the immunoprecipitated mucin probed with anti-SLe ${ }^{\mathrm{x}}$ antibody confirmed the presence of this epitope on MU5CAC (Fig. 6B). Overall, MUC5AC and SLe ${ }^{\mathrm{x}}$ colocalization was observed using both PLA and immunoprecipitation followed by western blotting.

\section{Discussion}

In this work we assessed the expression of MUC1 and MUC5AC as well as the cancer associated glycans SLe ${ }^{\mathrm{x}}$ and STn in pancreatic cancer tissues. Our results show the expression of $\mathrm{SLe}^{\mathrm{x}}$ in MUC5AC in most of the pancreatic cancer tissues as a promissing new biomarker of disease. Secreted mucins, such as MUC5AC, protect epithelial cells from different harsh microenvironments forming a protective layer that allows the selective passage of molecules. Transmembrane mucins, like MUC1, apart from being sensors of the external environment, are engaged in signal transduction. The cytoplasmic tail of MUC1 is involved in several signalling pathways including those concerning Ras, $\beta$-catenin, $\mathrm{p} 120$ catenin, $\mathrm{p} 53$ and estrogen receptor $\alpha$ [51]. In tumour state, cancer cells express normal and new mucin core proteins with aberrant glycan structures that arise during disease progression to acquire new capabilities $[8,22,40]$. Studies with interference RNA specifically targeting MUC1 and MUC5AC showed a reduction of PDAC cells to adhere and invade $[52,53]$, demonstrating the role of these mucins in PDAC progression and metastasis.

Mucins are considered a potential tool for the diagnosis and therapy of a wide range of cancers. More than 200 clinical studies have been conducted over the last three decades to evaluate mucins as therapeutic constituents or prognostic indicators [11,54-56].

PDAC is characterized by a lack of blood supply to tumours, whose surfaces are often coated with layers of dense, fibrous capsules, making the delivery of chemotherapy drugs difficult [7]. Target therapy using anti-MUC1 antibodies conjugated to radioactive elements and/or cytotoxic drugs that have shown to increase efficacy than radioimmunotherapy alone in prostate and ovarian cancers could 
be potentially useful in PDAC [6, 11]. Moreover, several studies show that MUC1 [57] and STn epitope [58] can be successful in activating the immune system when injected as vaccines in MUC1 transgenic mice.

There are several antibodies against MUC1 displaying different staining patterns and percentages of positivity in normal pancreas and PDAC tissues $[59,60]$. To our knowledge, this is the first time that the monoclonal antibody VU4H5 against MUC1 was used in the IHC analysis of pancreatic tissues. Considering that the specificity described for VU4H5 is against the non-glycosylated APDTRPAP epitope within the tandem repeat sequence of MUC1 [60-62], the low expression found in some tissues in this study could be explained by a possible glycosylation present on the MUC1 in PDAC. To address this issue, we have also used antibody M8 for the evaluation of MUC1 expression in the low MUC1 expressing cases, and higher positivity was observed. These results are in agreement with results from Hinoda and collaborators that found an increase in MUC1 detection in cancer tissues using an antibody directed against the core protein after deglycosylation [63].

On the other hand, MUC5AC is being considered an interesting target for PDAC detection due to its neo-expression in pancreas during malignant transformation $[6,64]$. Herein we showed the neoexpression of MUC5AC in PDAC in agreement with other authors [27-29, 40].

Regarding the expression of tumour-associated carbohydrate antigens $\mathrm{SLe}^{\mathrm{x}}$ and $\mathrm{STn}$, the detection in PDAC tissues and not in normal pancreas is in agreement with the reported literature [33-35]. The cancer associated expression of $\mathrm{SLe}^{\mathrm{x}}$ in pancreatic adenocarcinoma can be attributed to changes in glycosyltransferase expression [65]. An increase in $\alpha 2,3$-siayltransferases such as ST3GAL4 and in 1,3-fucosyltransferases such as FUT3 and FUT6 have been described in pancreatic adenocarcinoma tissues [66]. In addition, changes in nucleotide donor transporters and hypoxia have been reported to regulate SLe expression in colon cancer [67-69]. Since PDAC tumours are usually hypoxic due to poor vascularization [70] it is possible to postulate that the highly hypoxic environment of PDAC could be one of the factors inducing an increase in the glycosyltranferase expression and leading to an augment of SLe $\mathrm{e}^{\mathrm{x}}$ expression.

In this work we have addressed whether SLe ${ }^{\mathrm{x}}$ and/or STn could be carried on MUC1 and MUC5AC mucins in PDAC. The presence of the sialylated epitopes SLe ${ }^{\mathrm{x}}$ and STn on MUC1 and MUC5AC has 
been previously described by other authors in gastric, colon, lung, breast and ovarian cancer tissues $[17,39,42-45]$ as well as in pancreatic cancer cell line [71], using PLA and other antibody-based approaches. Since an increase of truncated structures is a key feature of tumour cells [72], we expected an increase in STn expression on MUC1 and MUC5AC. Although the expression of MUC1 bearing $\mathrm{Tn} / \mathrm{STn}$, detected by a specific anti-MUC1-Tn/STn antibody, in PDAC tissues has been reported by Remmers and collaborators [40], our results do not show the same tendency. This could be due to the use of different antibodies, different methodology and different cohort. We have used a specific antiSTn antibody and PLA technique to colocalize this antigen within the mucin proteins. Regarding the $\mathrm{SLe}^{\mathrm{x}}$ epitope on these mucins, our results show a wide colocalization of SLe ${ }^{\mathrm{x}}$ on MUC1 and especially on MUC5AC in PDAC tissues. Furthermore, the presence of SLe ${ }^{x}$ on MUC5AC was confirmed by immunoprecipitation of PDAC tissue protein lysates and subsequent Western blotting analysis using anti-SLe ${ }^{\mathrm{x}}$ antibodies. Our results show that both mucins are carriers of SLe ${ }^{\mathrm{x}}$ antigen in most PDAC tissues that expressed individually SLe ${ }^{\mathrm{x}}$ and the corresponding mucin. However, other glycoconjugates could also be carriers of SLe ${ }^{\mathrm{x}}$ antigen.

Most of the currently used cancer biomarkers assays take advantage of changes in the biodistribution of tumour cell derived products $[12,20,32]$, such as the diagnostic serum tests that are based on changes in the level of the circulating mucins, MUC16 (CA125) [73, 74] and MUC1 (CA15-3) [75], or changes in the mucin specific terminal glycan structures sialyl-Lewis a (CA19-9)[76, 77] or STn (CA72-4) $[78,79]$. To date, there is no specific tumour marker to diagnose PDAC. The only marker approved by FDA to manage PDAC is CA19-9 that detects sialyl-Lewis a, an epitope found mainly on mucins [80]. Some mucin-based markers lack specificity due to their detection also in benign conditions. Glycan-based markers, on the other hand, present low tissue specificity since aberrant $O$ glycans can be found in many carcinoma tissues. Therefore, our strategy was the detection of a specific glycoform on a specific mucin that could circumvent these weaknesses and generate a biomarker with potential application for specific PDAC detection.

A good biomarker should be a molecule that can be found in blood or other fluids. However, due to the pathophysiology and micro-architecture of PDAC, which is poorly perfused and vascularized, secreted proteins that could be candidates for biomarkers have rarely been detected in circulation [81]. 


\section{Acknowledgements}

M.B. acknowledges University of Girona for a pre-doctoral fellowship and a mobility grant. We also thank David Carreras for part of the IHC analysis. The authors also thank Dr. Carme de Bolós from Gastroesophagic Cancer Research Group, Hospital del Mar Medical Research Institute (IMIM), for kindly providing anti-MUC5AC rabbit polyclonal antibody Lum5.1. This work was supported by Spanish Ministry of Science and Innovation (grant BIO 2015-66356-R, awarded to R.P.). C.A.R. acknowledges the support by Gastric Glyco Explorer Initial Training Network (Seventh Framework Programme, project GastricGlycoExplorer, grant number 316929), and Fundação para a Ciência e 
Tecnologia, project PTDC/BBB-EBI/0567/2014 (POCI-010145-FEDER-016585) and NORTE 2020

(NORTE-01-0145-FEDER-000029).

\section{References}

[1] R.L. Siegel, K.D. Miller, A. Jemal, Cancer statistics, 2016, CA Cancer J Clin 66(1) (2016) 7-30.

[2] L. Rahib, B.D. Smith, R. Aizenberg, A.B. Rosenzweig, J.M. Fleshman, L.M. Matrisian, Projecting cancer incidence and deaths to 2030: the unexpected burden of thyroid, liver, and pancreas cancers in the United States, Cancer Res 74(11) (2014) 2913-21.

[3] R. Freelove, A.D. Walling, Pancreatic cancer: diagnosis and management, Am Fam Physician 73(3) (2006) 485-92.

[4] M. Malvezzi, P. Bertuccio, F. Levi, C. La Vecchia, E. Negri, European cancer mortality predictions for the year 2014, Ann Oncol 25(8) (2014) 1650-6.

[5] T. Kamisawa, L.D. Wood, T. Itoi, K. Takaori, Pancreatic cancer, Lancet (2016).

[6] N. Jonckheere, N. Skrypek, I. Van Seuningen, Mucins and pancreatic cancer, Cancers (Basel) 2(4) (2010) 1794-812.

[7] H.Y. Li, Z.M. Cui, J. Chen, X.Z. Guo, Y.Y. Li, Pancreatic cancer: diagnosis and treatments, Tumour biology : the journal of the International Society for Oncodevelopmental Biology and Medicine (2015).

[8] M.A. Hollingsworth, B.J. Swanson, Mucins in cancer: protection and control of the cell surface, Nat Rev Cancer 4(1) (2004) 45-60.

[9] A.P. Corfield, Mucins: a biologically relevant glycan barrier in mucosal protection, Biochim Biophys Acta 1850(1) (2015) 236-52.

[10] S. Parry, H.S. Silverman, K. McDermott, A. Willis, M.A. Hollingsworth, A. Harris, Identification of MUC1 proteolytic cleavage sites in vivo, Biochemical and biophysical research communications 283(3) (2001) 715-20.

[11] S. Rachagani, M.P. Torres, N. Moniaux, S.K. Batra, Current status of mucins in the diagnosis and therapy of cancer, Biofactors 35(6) (2009) 509-27.

[12] C.A. Reis, H. Osorio, L. Silva, C. Gomes, L. David, Alterations in glycosylation as biomarkers for cancer detection, J Clin Pathol 63(4) (2010) 322-9.

[13] A.C. Kolbl, U. Andergassen, U. Jeschke, The Role of Glycosylation in Breast Cancer Metastasis and Cancer Control, Front Oncol 5 (2015) 219.

[14] H. Kawashima, Roles of the gel-forming MUC2 mucin and its O-glycosylation in the protection against colitis and colorectal cancer, Biol Pharm Bull 35(10) (2012) 1637-41.

[15] C. Robbe-Masselot, A. Herrmann, E. Maes, I. Carlstedt, J.C. Michalski, C. Capon, Expression of a core 3 disialyl-Le $(\mathrm{x})$ hexasaccharide in human colorectal cancers: a potential marker of malignant transformation in colon, J Proteome Res 8(2) (2009) 702-11.

[16] C. de Bolos, F.X. Real, A. Lopez-Ferrer, Regulation of mucin and glycoconjugate expression: from normal epithelium to gastric tumors, Front Biosci 6 (2001) D1256-63.

[17] C.A. Reis, L. David, M. Seixas, J. Burchell, M. Sobrinho-Simoes, Expression of fully and underglycosylated forms of MUC1 mucin in gastric carcinoma, Int J Cancer 79(4) (1998) 402-10.

[18] C. Jin, D.T. Kenny, E.C. Skoog, M. Padra, B. Adamczyk, V. Vitizeva, A. Thorell, V. Venkatakrishnan, S.K. Linden, N.G. Karlsson, Structural Diversity of Human Gastric Mucin Glycans, Mol Cell Proteomics 16(5) (2017) 743-758.

[19] V.B. Chachadi, G. Bhat, P.W. Cheng, Glycosyltransferases involved in the synthesis of MUCassociated metastasis-promoting selectin ligands, Glycobiology 25(9) (2015) 963-75.

[20] R. Peracaula, S. Barrabes, A. Sarrats, P.M. Rudd, R. de Llorens, Altered glycosylation in tumours focused to cancer diagnosis, Dis Markers 25(4-5) (2008) 207-18.

[21] N. Moniaux, M. Andrianifahanana, R.E. Brand, S.K. Batra, Multiple roles of mucins in pancreatic cancer, a lethal and challenging malignancy, Br J Cancer 91(9) (2004) 1633-8. 
[22] D.W. Kufe, Mucins in cancer: function, prognosis and therapy, Nat Rev Cancer 9(12) (2009) 87485.

[23] S.S. Pinho, C.A. Reis, Glycosylation in cancer: mechanisms and clinical implications, Nat Rev Cancer 15(9) (2015) 540-55.

[24] M.D. Burdick, A. Harris, C.J. Reid, T. Iwamura, M.A. Hollingsworth, Oligosaccharides expressed on MUC1 produced by pancreatic and colon tumor cell lines, The Journal of biological chemistry 272(39) (1997) 24198-202.

[25] S.B. Ho, G.A. Niehans, C. Lyftogt, P.S. Yan, D.L. Cherwitz, E.T. Gum, R. Dahiya, Y.S. Kim, Heterogeneity of mucin gene expression in normal and neoplastic tissues, Cancer Res 53(3) (1993) 641-51.

[26] C. Balague, G. Gambus, C. Carrato, N. Porchet, J.P. Aubert, Y.S. Kim, F.X. Real, Altered expression of MUC2, MUC4, and MUC5 mucin genes in pancreas tissues and cancer cell lines, Gastroenterology 106(4) (1994) 1054-61.

[27] G.E. Kim, H.I. Bae, H.U. Park, S.F. Kuan, S.C. Crawley, J.J. Ho, Y.S. Kim, Aberrant expression of MUC5AC and MUC6 gastric mucins and sialyl Tn antigen in intraepithelial neoplasms of the pancreas, Gastroenterology 123(4) (2002) 1052-60.

[28] S.K. Lau, L.M. Weiss, P.G. Chu, Differential expression of MUC1, MUC2, and MUC5AC in carcinomas of various sites: an immunohistochemical study, Am J Clin Pathol 122(1) (2004) 61-9. [29] S. Yonezawa, M. Higashi, N. Yamada, M. Goto, Precursor lesions of pancreatic cancer, Gut Liver 2(3) (2008) 137-54.

[30] S. Hakomori, Aberrant glycosylation in tumors and tumor-associated carbohydrate antigens, Adv Cancer Res 52 (1989) 257-331.

[31] K.R. Varki A, Toole BP, Glycosylation Changes in Cancer. Essentials of Glycobiology., in: C.R. Varki A, Esko JD, Freeze HH, Stanley P, Bertozzi CR, Hart GW, Etzler ME (Ed.) Cold Spring Harbour Laboratory Press, New Yord, 2009.

[32] S.R. Stowell, T. Ju, R.D. Cummings, Protein glycosylation in cancer, Annu Rev Pathol 10 (2015) 473-510.

[33] Y. Satomura, N. Sawabu, Y. Takemori, H. Ohta, H. Watanabe, T. Okai, K. Watanabe, H. Matsuno, F. Konishi, Expression of various sialylated carbohydrate antigens in malignant and nonmalignant pancreatic tissues, Pancreas 6(4) (1991) 448-58.

[34] S. Bassaganas, H. Allende, L. Cobler, M.R. Ortiz, E. Llop, C. de Bolos, R. Peracaula, Inflammatory cytokines regulate the expression of glycosyltransferases involved in the biosynthesis of tumorassociated sialylated glycans in pancreatic cancer cell lines, Cytokine (2015).

[35] S. Julien, P.A. Videira, P. Delannoy, Sialyl-tn in cancer: (how) did we miss the target?, Biomolecules 2(4) (2012) 435-66.

[36] D.H. Dube, C.R. Bertozzi, Glycans in cancer and inflammation--potential for therapeutics and diagnostics, Nat Rev Drug Discov 4(6) (2005) 477-88.

[37] T. Terada, Y. Nakanuma, Expression of mucin carbohydrate antigens ( $T$, Tn and sialyl Tn) and MUC-1 gene product in intraductal papillary-mucinous neoplasm of the pancreas, Am J Clin Pathol 105(5) (1996) 613-20.

[38] I. Häuselmann, L. Borsig, Altered Tumor-Cell Glycosylation Promotes Metastasis, Front Oncol 4 (2014).

[39] R. Pinto, A.S. Carvalho, T. Conze, A. Magalhaes, G. Picco, J.M. Burchell, J. Taylor-Papadimitriou, C.A. Reis, R. Almeida, U. Mandel, H. Clausen, O. Soderberg, L. David, Identification of new cancer biomarkers based on aberrant mucin glycoforms by in situ proximity ligation, J Cell Mol Med 16(7) (2012) 1474-84.

[40] N. Remmers, J.M. Anderson, E.M. Linde, D.J. DiMaio, A.J. Lazenby, H.H. Wandall, U. Mandel, H. Clausen, F. Yu, M.A. Hollingsworth, Aberrant expression of mucin core proteins and o-linked glycans associated with progression of pancreatic cancer, Clin Cancer Res 19(8) (2013) 1981-93.

[41] A.L. Sorensen, C.A. Reis, M.A. Tarp, U. Mandel, K. Ramachandran, V. Sankaranarayanan, T. Schwientek, R. Graham, J. Taylor-Papadimitriou, M.A. Hollingsworth, J. Burchell, H. Clausen, 
Chemoenzymatically synthesized multimeric Tn/STn MUC1 glycopeptides elicit cancer-specific antiMUC1 antibody responses and override tolerance, Glycobiology 16(2) (2006) 96-107.

[42] J.M. Yang, J.C. Byrd, B.B. Siddiki, Y.S. Chung, M. Okuno, M. Sowa, Y.S. Kim, K.L. Matta, I. Brockhausen, Alterations of O-glycan biosynthesis in human colon cancer tissues, Glycobiology 4(6) (1994) 873-84.

[43] K. Zhang, D. Baeckstrom, H. Brevinge, G.C. Hansson, Secreted MUC1 mucins lacking their cytoplasmic part and carrying sialyl-Lewis a and $\mathrm{x}$ epitopes from a tumor cell line and sera of colon carcinoma patients can inhibit HL-60 leukocyte adhesion to E-selectin-expressing endothelial cells, J Cell Biochem 60(4) (1996) 538-49.

[44] V.B. Chachadi, H. Cheng, D. Klinkebiel, J.K. Christman, P.W. Cheng, 5-Aza-2'-deoxycytidine increases sialyl Lewis X on MUC1 by stimulating beta-galactoside:alpha2,3-sialyltransferase 6 gene, Int J Biochem Cell Biol 43(4) (2011) 586-93.

[45] R. Sikut, K. Zhang, D. Baeckstrom, G.C. Hansson, Distinct sub-populations of carcinomaassociated MUC1 mucins as detected by the monoclonal antibody $9 \mathrm{H} 8$ and antibodies against the sialyl-Lewis a and sialyl-Lewis $\mathrm{x}$ epitopes in the circulation of breast-cancer patients, Int $\mathrm{J}$ Cancer 66(5) (1996) 617-23.

[46] L.H. Sobin, C.C. Compton, TNM seventh edition: what's new, what's changed: communication from the International Union Against Cancer and the American Joint Committee on Cancer, Cancer 116(22) (2010) 5336-9.

[47] R. Peracaula, K.R. Cleary, J. Lorenzo, R. de Llorens, M.L. Frazier, Human pancreatic ribonuclease 1: expression and distribution in pancreatic adenocarcinoma, Cancer 89(6) (2000) 1252-8.

[48] A. Bouillez, V. Gnemmi, K. Gaudelot, B. Hemon, B. Ringot, N. Pottier, F. Glowacki, C. Butruille, C. Cauffiez, M. Hamdane, N. Sergeant, I. Van Seuningen, X. Leroy, S. Aubert, M. Perrais, MUC1-C nuclear localization drives invasiveness of renal cancer cells through a sheddase/gamma secretase dependent pathway, Oncotarget 5(3) (2014) 754-63.

[49] R.A. Mcllhinney, S. Patel, M.E. Gore, Monoclonal antibodies recognizing epitopes carried on both glycolipids and glycoproteins of the human milk fat globule membrane, Biochem J 227(1) (1985) 15562.

[50] S. Mereiter, M. Balmana, J. Gomes, A. Magalhaes, C.A. Reis, Glycomic Approaches for the Discovery of Targets in Gastrointestinal Cancer, Front Oncol 6 (2016) 55.

[51] P.K. Singh, M.A. Hollingsworth, Cell surface-associated mucins in signal transduction, Trends Cell Biol 16(9) (2006) 467-76.

[52] H. Tsutsumida, B.J. Swanson, P.K. Singh, T.C. Caffrey, S. Kitajima, M. Goto, S. Yonezawa, M.A. Hollingsworth, RNA interference suppression of MUC1 reduces the growth rate and metastatic phenotype of human pancreatic cancer cells, Clin Cancer Res 12(10) (2006) 2976-87.

[53] S. Yamazoe, H. Tanaka, T. Sawada, R. Amano, N. Yamada, M. Ohira, K. Hirakawa, RNA interference suppression of mucin $5 A C$ (MUC5AC) reduces the adhesive and invasive capacity of human pancreatic cancer cells, Journal of experimental \& clinical cancer research : CR 29 (2010) 53. [54] M.P. Torres, S. Chakraborty, J. Souchek, S.K. Batra, Mucin-based targeted pancreatic cancer therapy, Curr Pharm Des 18(17) (2012) 2472-81.

[55] B.G. Bitler, I. Menzl, C.L. Huerta, B. Sands, W. Knowlton, A. Chang, J.A. Schroeder, Intracellular MUC1 peptides inhibit cancer progression, Clin Cancer Res 15(1) (2009) 100-9.

[56] D.V. Gold, G. Newsome, D. Liu, D.M. Goldenberg, Mapping PAM4 (clivatuzumab), a monoclonal antibody in clinical trials for early detection and therapy of pancreatic ductal adenocarcinoma, to MUC5AC mucin, Molecular cancer 12(1) (2013) 143.

[57] P. Mukherjee, L.B. Pathangey, J.B. Bradley, T.L. Tinder, G.D. Basu, E.T. Akporiaye, S.J. Gendler, MUC1-specific immune therapy generates a strong anti-tumor response in a MUC1-tolerant colon cancer model, Vaccine 25(9) (2007) 1607-18.

[58] S. Julien, G. Picco, R. Sewell, A.S. Vercoutter-Edouart, M. Tarp, D. Miles, H. Clausen, J. TaylorPapadimitriou, J.M. Burchell, Sialyl-Tn vaccine induces antibody-mediated tumour protection in a relevant murine model, Br J Cancer 100(11) (2009) 1746-54. 
[59] S. Yonezawa, M. Higashi, N. Yamada, S. Yokoyama, M. Goto, Significance of mucin expression in pancreatobiliary neoplasms, J Hepatobiliary Pancreat Sci 17(2) (2010) 108-24.

[60] M.R. Price, P.D. Rye, E. Petrakou, A. Murray, K. Brady, S. Imai, S. Haga, Y. Kiyozuka, D. Schol, M.F. Meulenbroek, F.G. Snijdewint, S. von Mensdorff-Pouilly, R.A. Verstraeten, P. Kenemans, A. Blockzjil, K. Nilsson, O. Nilsson, M. Reddish, M.R. Suresh, R.R. Koganty, S. Fortier, L. Baronic, A. Berg, M.B. Longenecker, J. Hilgers, et al., Summary report on the ISOBM TD-4 Workshop: analysis of 56 monoclonal antibodies against the MUC1 mucin. San Diego, Calif., November 17-23, 1996, Tumour biology : the journal of the International Society for Oncodevelopmental Biology and Medicine 19 Suppl 1 (1998) 1-20.

[61] D.J. Schol, M.F. Meulenbroek, F.G. Snijdewint, S. von Mensdorff-Pouilly, R.A. Verstraeten, F. Murakami, P. Kenemans, J. Hilgers, 'Epitope fingerprinting' using overlapping 20-mer peptides of the MUC1 tandem repeat sequence, Tumour biology : the journal of the International Society for Oncodevelopmental Biology and Medicine 19 Suppl 1 (1998) 35-45.

[62] N.T. Marcos, A. Cruz, F. Silva, R. Almeida, L. David, U. Mandel, H. Clausen, S. Von MensdorffPouilly, C.A. Reis, Polypeptide GalNAc-transferases, ST6GalNAc-transferase I, and ST3Gal-transferase I expression in gastric carcinoma cell lines, The journal of histochemistry and cytochemistry : official journal of the Histochemistry Society 51(6) (2003) 761-71.

[63] Y. Hinoda, T. Takahashi, T. Hayashi, T. Suwa, Y. Makiguchi, F. Itoh, M. Adachi, K. Imai, Enhancement of reactivity of anti-MUC1 core protein antibody and killing activity of anti-MUC1 cytotoxic T cells by deglycosylation of target tissues or cells, J Gastroenterol 33(2) (1998) 164-71. [64] F. Lin, Z.E. Chen, H.L. Wang, Utility of immunohistochemistry in the pancreatobiliary tract, Archives of pathology \& laboratory medicine 139(1) (2015) 24-38.

[65] M. Trinchera, A. Aronica, F. Dall'Olio, Selectin Ligands Sialyl-Lewis a and Sialyl-Lewis $x$ in Gastrointestinal Cancers, Biology (Basel) 6(1) (2017).

[66] M. Perez-Garay, B. Arteta, E. Llop, L. Cobler, L. Pages, R. Ortiz, M.J. Ferri, C. de Bolos, J. Figueras, R. de Llorens, F. Vidal-Vanaclocha, R. Peracaula, alpha2,3-Sialyltransferase ST3Gal IV promotes migration and metastasis in pancreatic adenocarcinoma cells and tends to be highly expressed in pancreatic adenocarcinoma tissues, Int J Biochem Cell Biol 45(8) (2013) 1748-57.

[67] K. Kumamoto, Y. Goto, K. Sekikawa, S. Takenoshita, N. Ishida, M. Kawakita, R. Kannagi, Increased expression of UDP-galactose transporter messenger RNA in human colon cancer tissues and its implication in synthesis of Thomsen-Friedenreich antigen and sialyl Lewis $A / X$ determinants, Cancer Res 61(11) (2001) 4620-7.

[68] A. Yusa, K. Miyazaki, N. Kimura, M. Izawa, R. Kannagi, Epigenetic silencing of the sulfate transporter gene DTDST induces sialyl Lewisx expression and accelerates proliferation of colon cancer cells, Cancer Res 70(10) (2010) 4064-73.

[69] T. Koike, N. Kimura, K. Miyazaki, T. Yabuta, K. Kumamoto, S. Takenoshita, J. Chen, M. Kobayashi, M. Hosokawa, A. Taniguchi, T. Kojima, N. Ishida, M. Kawakita, H. Yamamoto, H. Takematsu, A. Suzuki, Y. Kozutsumi, R. Kannagi, Hypoxia induces adhesion molecules on cancer cells: A missing link between Warburg effect and induction of selectin-ligand carbohydrates, Proc Natl Acad Sci U S A 101(21) (2004) 8132-7.

[70] M. Erkan, M. Kurtoglu, J. Kleeff, The role of hypoxia in pancreatic cancer: a potential therapeutic target?, Expert Rev Gastroenterol Hepatol 10(3) (2016) 301-16.

[71] J.J. Ho, B. Siddiki, Y.S. Kim, Association of sialyl-Lewis(a) and sialyl-Lewis(x) with MUC-1 apomucin ina pancreatic cancer cell line, Cancer Res 55(16) (1995) 3659-63.

[72] R. Kannagi, J. Yin, K. Miyazaki, M. Izawa, Current relevance of incomplete synthesis and neosynthesis for cancer-associated alteration of carbohydrate determinants--Hakomori's concepts revisited, Biochim Biophys Acta 1780(3) (2008) 525-31.

[73] P. Petignat, F. Joris, R. Obrist, How CA 125 is used in routine clinical practice, Eur J Cancer 36(15) (2000) 1933-7.

[74] R. Saldova, W.B. Struwe, K. Wynne, G. Elia, M.J. Duffy, P.M. Rudd, Exploring the glycosylation of serum CA125, Int J Mol Sci 14(8) (2013) 15636-54. 
[75] M.J. Duffy, C. Duggan, R. Keane, A.D. Hill, E. McDermott, J. Crown, N. O'Higgins, High preoperative CA 15-3 concentrations predict adverse outcome in node-negative and node-positive breast cancer: study of 600 patients with histologically confirmed breast cancer, Clin Chem 50(3) (2004) 559-63.

[76] U.K. Ballehaninna, R.S. Chamberlain, The clinical utility of serum CA 19-9 in the diagnosis, prognosis and management of pancreatic adenocarcinoma: An evidence based appraisal, J Gastrointest Oncol 3(2) (2012) 105-19.

[77] D.A. Parikh, B. Durbin-Johnson, S. Urayama, Utility of serum CA19-9 levels in the diagnosis of pancreatic ductal adenocarcinoma in an endoscopic ultrasound referral population, J Gastrointest Cancer 45(1) (2014) 74-9.

[78] M. Ychou, J. Duffour, A. Kramar, S. Gourgou, J. Grenier, Clinical significance and prognostic value of CA72-4 compared with CEA and CA19-9 in patients with gastric cancer, Dis Markers 16(3-4) (2000) 105-10.

[79] J. Louhimo, H. Alfthan, U.H. Stenman, C. Haglund, Serum HCG beta and CA 72-4 are stronger prognostic factors than CEA, CA 19-9 and CA 242 in pancreatic cancer, Oncology 66(2) (2004) 126-31. [80] T. Yue, K.A. Maupin, B. Fallon, L. Li, K. Partyka, M.A. Anderson, D.E. Brenner, K. Kaul, H. Zeh, A.J. Moser, D.M. Simeone, Z. Feng, R.E. Brand, B.B. Haab, Enhanced discrimination of malignant from benign pancreatic disease by measuring the CA 19-9 antigen on specific protein carriers, PLoS One 6(12) (2011) e29180.

[81] F. Ruckert, C. Pilarsky, R. Grutzmann, Serum tumor markers in pancreatic cancer-recent discoveries, Cancers (Basel) 2(2) (2010) 1107-24.

[82] C. Jenkinson, J. Earl, P. Ghaneh, C. Halloran, A. Carrato, W. Greenhalf, J. Neoptolemos, E. Costello, Biomarkers for early diagnosis of pancreatic cancer, Expert Rev Gastroenterol Hepatol 9(3) (2015) 305-15.

[83] C. Sun, A.H. Rosendahl, D. Ansari, R. Andersson, Proteome-based biomarkers in pancreatic cancer, World journal of gastroenterology : WJG 17(44) (2011) 4845-52.

[84] C.A. Reis, L. David, P.A. Nielsen, H. Clausen, K. Mirgorodskaya, P. Roepstorff, M. SobrinhoSimoes, Immunohistochemical study of MUC5AC expression in human gastric carcinomas using a novel monoclonal antibody, Int J Cancer 74(1) (1997) 112-21.

[85] H.W. Hovenberg, J.R. Davies, I. Carlstedt, Different mucins are produced by the surface epithelium and the submucosa in human trachea: identification of MUC5AC as a major mucin from the goblet cells, Biochem J 318 ( Pt 1) (1996) 319-24.

[86] M.R. Price, F. Hudecz, C. O'Sullivan, R.W. Baldwin, P.M. Edwards, S.J. Tendler, Immunological and structural features of the protein core of human polymorphic epithelial mucin, Mol Immunol 27(8) (1990) 795-802.

[87] C.S. Foster, E.A. Dinsdale, P.A. Edwards, A.M. Neville, Monoclonal antibodies to the human mammary gland. II. Distribution of determinants in breast carcinomas, Virchows Arch A Pathol Anat Histol 394(3) (1982) 295-305.

[88] C.S. Foster, P.A. Edwards, E.A. Dinsdale, A.M. Neville, Monoclonal antibodies to the human mammary gland. I. Distribution of determinants in non-neoplastic mammary and extra mammary tissues, Virchows Arch A Pathol Anat Histol 394(3) (1982) 279-93.

[89] T. Kjeldsen, H. Clausen, S. Hirohashi, T. Ogawa, H. lijima, S. Hakomori, Preparation and characterization of monoclonal antibodies directed to the tumor-associated O-linked sialosyl-2----6 alpha-N-acetylgalactosaminyl (sialosyl-Tn) epitope, Cancer Res 48(8) (1988) 2214-20. 
Table 1: Antibodies used for immunohistochemistry and Western blotting.

\begin{tabular}{l|lll}
\hline \multicolumn{1}{c}{ Antibody } & Isotype & Concentration & Antigen and reference \\
\hline CLH2 & IgG2 & $0.60 \mathrm{ng} / \mu \mathrm{L}$ & MUC5AC [84] \\
KM93 & IgM & $\begin{array}{l}2.5 \mathrm{ng} / \mu \mathrm{L} \text { IHC/PLA } \\
3.3 \mathrm{ng} / \mu \mathrm{L} \text { western blotting }\end{array}$ & $\begin{array}{l}\text { SLe } \\
\text { Darmstadt, Germany) }\end{array}$ \\
LUM5.1 & polyclonal & $\begin{array}{l}\text { Rabbit polyclonal serum diluted } \\
1 / 1000 \text { western blotting }\end{array}$ & MUC5AC [85] \\
M8 & IgG1 & Supernatant diluted $1 / 2$ & MUC1 [86-88] \\
TKH2 & IgG1 & $0.95 \mathrm{ng} / \mu \mathrm{L}$ & STn [89] \\
VU4H5 & $\operatorname{IgG1}$ & $1.19 \mathrm{ng} / \mu \mathrm{L}$ & MUC1 [60-62] \\
\hline
\end{tabular}


Table 2: Carbohydrate epitopes SLe ${ }^{\mathrm{x}}$ and STn expression in pancreatic tissues.

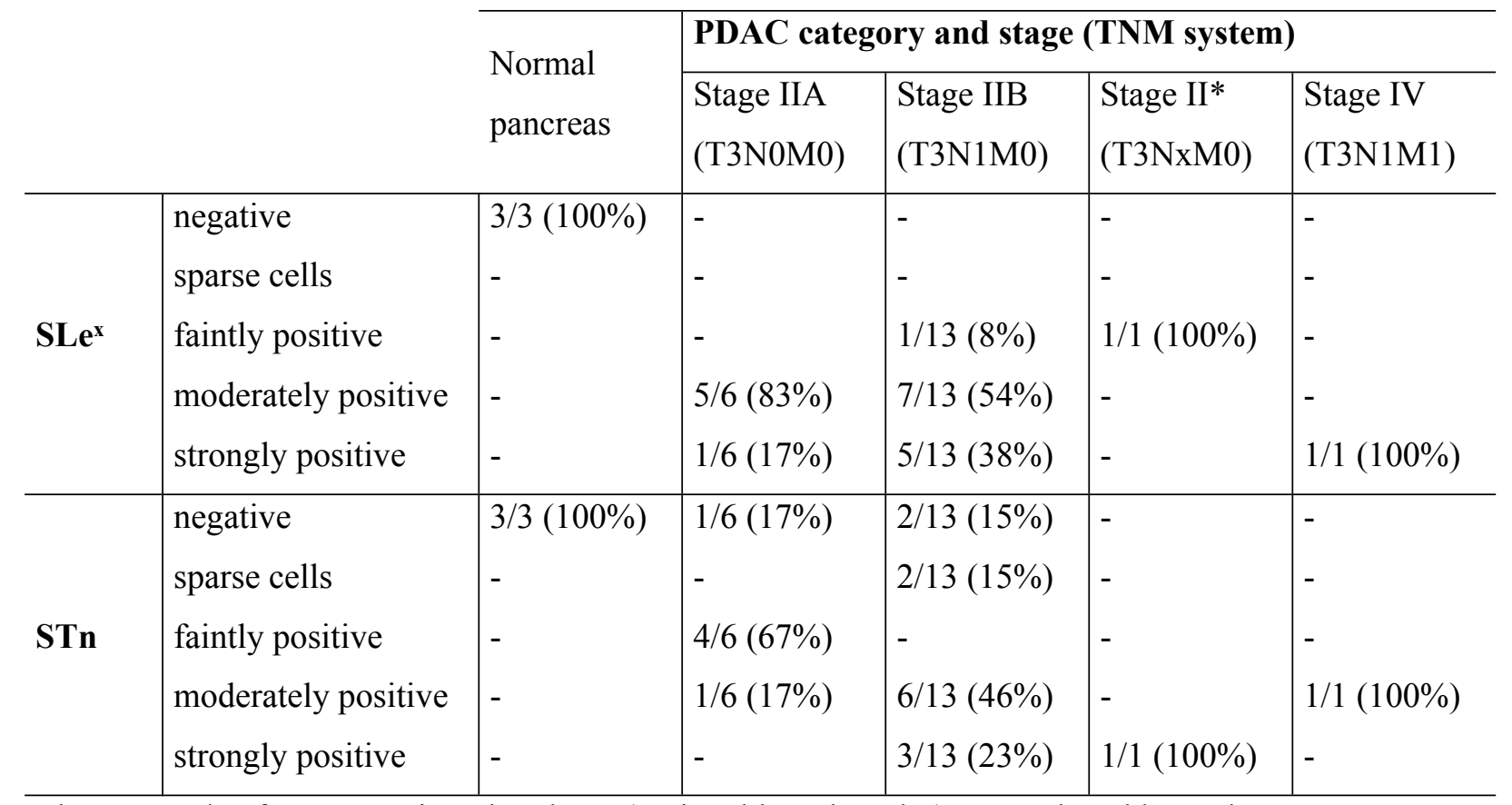

The stage II* refers to a patient that the $\mathrm{N}$ (regional lymph nodes) cannot be addressed. 
Table 3. Carbohydrate epitopes SLe ${ }^{x}$ and STn and mucins MUC1 and MUC5AC expression in each of the pancreatic tissues analysed.

\section{Category and stage}

(TNM system)

Cases

\section{Differentiation} grade $^{1}$

Gender Age SLe ${ }^{x}$ STn MUC1

MUC5AC

\begin{tabular}{|c|c|c|c|c|c|c|c|c|c|}
\hline & & & - & $\mathrm{M}$ & 65 & - & - & +++ & - \\
\hline Normal & Pancreas & 3 & - & $\mathrm{F}$ & 76 & - & - & +++ & - \\
\hline & & & - & $\mathrm{F}$ & 61 & - & - & +++ & - \\
\hline & & & MD & $\mathrm{M}$ & 70 & ++ & + & +++ & +++ \\
\hline & & & MD & M & 65 & ++ & + & ++ & ++ \\
\hline & Stage IIA & & MD & M & 61 & ++ & ++ & ++ & ++ \\
\hline & (T3N0M0) & 6 & PD & M & 65 & ++ & ++ & +++ & + \\
\hline & & & WD/MD & M & 71 & +++ & - & $\mathrm{sc}$ & - \\
\hline & & & MD/PD & M & 70 & ++ & + & + & + \\
\hline & & & MD & $\mathrm{M}$ & 57 & ++ & ++ & ++ & + \\
\hline & & & MD & M & 72 & +++ & ++ & +++ & ++ \\
\hline & & & WD & $\mathrm{F}$ & 70 & ++ & +++ & ++ & +++ \\
\hline & & & PD & M & 58 & ++ & ++ & +++ & ++ \\
\hline & & & WD & M & 72 & +++ & ++ & ++ & + \\
\hline PDAC & & & WD & $\mathrm{F}$ & 49 & +++ & - & + & - \\
\hline & Stage IIB & 13 & WD & $\mathrm{F}$ & 78 & +++ & +++ & + & +++ \\
\hline & & & PD & M & 81 & ++ & $\mathrm{sc}$ & +++ & + \\
\hline & & & MD & $\mathrm{F}$ & 71 & ++ & ++ & $\mathrm{sc}$ & ++ \\
\hline & & & $\mathrm{MD}$ & M & 67 & ++ & ++ & +++ & ++ \\
\hline & & & WD/MD & $\mathrm{F}$ & 66 & ++ & - & ++ & ++ \\
\hline & & & MD & $\mathrm{F}$ & 57 & + & $\mathrm{sc}$ & ++ & + \\
\hline & & & MD & $\mathrm{M}$ & 79 & ++ & +++ & +++ & +++ \\
\hline & $\begin{array}{l}\text { Stage II* } \\
\text { (T3NxM0) }\end{array}$ & 1 & MD & $\mathrm{M}$ & 65 & + & +++ & +++ & +++ \\
\hline & $\begin{array}{l}\text { Stage IV } \\
\text { (T3N1M1) }\end{array}$ & 1 & WD & $\mathrm{M}$ & 76 & +++ & ++ & +++ & +++ \\
\hline
\end{tabular}

Staining intensity is graded as: negative: -, sparse cells: sc; faintly positive (10-25\% stained cells): + ; moderately positive (25-60\% stained cells): ++ ; and strongly positive ( $>60 \%$ stained cells): +++ .

The stage II* refers to a patient that the $\mathrm{N}$ (regional lymph nodes) cannot be addressed.

${ }^{1}$ Differentiation grade: PD: poorly differentiated, MD: moderately differentiated, and WD: well differentiated. 
Table 4: Mucins MUC1 and MUC5AC expression in pancreatic tissues.

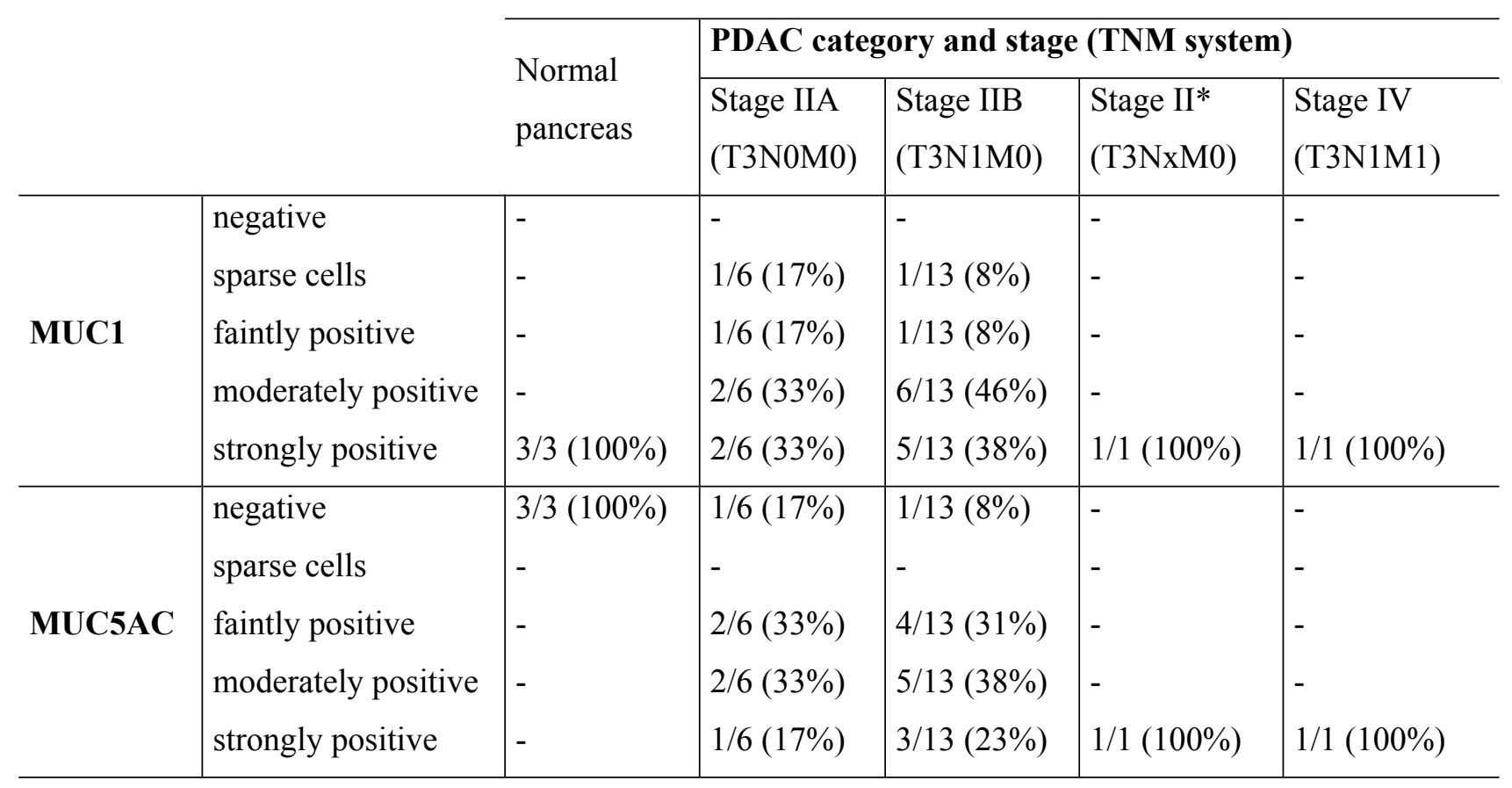

The stage II* refers to a patient that the $\mathrm{N}$ (regional lymph nodes) cannot be addressed. 
Table 5: Immunohistochemistry results for mucins and tumour-associated antigens and their colocalization by in situ PLA.

\begin{tabular}{lllll|llll}
\cline { 2 - 7 } & \multicolumn{1}{l}{ Immunohistochemistry } & & \multicolumn{4}{l}{ In situ PLA } \\
\cline { 2 - 4 } & MUC5AC & SLe $^{\mathrm{x}}$ & STn & $\begin{array}{l}\text { MUC1- } \\
\text { SLe }\end{array}$ & $\begin{array}{l}\text { MUC5AC- } \\
\text { SLe }\end{array}$ & $\begin{array}{l}\text { MUC1- } \\
\text { STn }\end{array}$ & $\begin{array}{l}\text { MUC5AC- } \\
\text { STn }\end{array}$ \\
\hline $\begin{array}{l}\text { Normal } \\
\text { pancreas }\end{array}$ & $3 / 3$ & $0 / 3$ & $0 / 3$ & $0 / 3$ & $0 / 3$ & $0 / 3$ & $0 / 3$ & $0 / 3$ \\
\hline \multirow{2}{*}{ Tumour } & $19 / 21$ & $19 / 21$ & $21 / 21$ & $16 / 21$ & $13 / 19$ & $16 / 19$ & $4 / 15^{\#}$ & $2 / 16$ \\
& $(90 \%)$ & $(90 \%)$ & $(100 \%)$ & $(76 \%)$ & $(68 \%)$ & $(84 \%)$ & $(27 \%)$ & $(13 \%)$ \\
\hline
\end{tabular}

\#15 PDAC tissues were positive for both MUC1 and STn by IHC. 


\section{Table 6: Immunohistochemistry results for mucins and $\mathrm{SLe}^{\mathrm{x}}$ and their colocalization by in situ}

\section{PLA.}

\begin{tabular}{|c|c|c|c|c|c|c|c|c|}
\hline \multicolumn{2}{|c|}{$\begin{array}{l}\text { Category and } \\
\text { stage (TNM system) }\end{array}$} & \multirow[t]{2}{*}{ Cases } & $\begin{array}{l}\text { Differen. } \\
\text { grade }^{1}\end{array}$ & $\operatorname{SLe}^{\mathrm{x}}$ & MUC1 & $\begin{array}{c}\text { PLA } \\
\text { MUC1- } \\
\text { SLe }^{x} \\
\end{array}$ & MUC5AC & $\begin{array}{c}\text { PLA } \\
\text { MUC5AC- } \\
\text { SLe }^{x}\end{array}$ \\
\hline \multirow{3}{*}{\multicolumn{2}{|c|}{ Normal Pancreas }} & & - & - & +++ & - & - & - \\
\hline & & \multirow[t]{2}{*}{3} & - & - & +++ & - & - & - \\
\hline & & & - & - & +++ & - & - & - \\
\hline \multirow{21}{*}{ PDAC } & \multirow{6}{*}{$\begin{array}{l}\text { Stage IIA } \\
\text { (T3N0M0) }\end{array}$} & \multirow{6}{*}{6} & MD & ++ & +++ & ++ & +++ & + \\
\hline & & & MD & ++ & ++ & +++ & ++ & + \\
\hline & & & MD & ++ & ++ & ++ & ++ & ++ \\
\hline & & & $\mathrm{PD}$ & ++ & +++ & + & + & - \\
\hline & & & WD/MD & +++ & $\mathrm{sc}$ & - & - & - \\
\hline & & & $\mathrm{MD} / \mathrm{PD}$ & ++ & + & - & + & +++ \\
\hline & \multirow{13}{*}{$\begin{array}{l}\text { Stage IIB } \\
\text { (T3N1M0) }\end{array}$} & \multirow{13}{*}{13} & $\mathrm{MD}$ & ++ & ++ & + & + & ++ \\
\hline & & & MD & +++ & +++ & ++ & ++ & - \\
\hline & & & WD & ++ & ++ & - & +++ & +++ \\
\hline & & & $\mathrm{PD}$ & ++ & +++ & +++ & ++ & ++ \\
\hline & & & WD & +++ & ++ & - & + & - \\
\hline & & & WD & +++ & + & - & - & - \\
\hline & & & WD & +++ & + & +++ & +++ & +++ \\
\hline & & & $\mathrm{PD}$ & ++ & +++ & - & + & + \\
\hline & & & MD & ++ & $\mathrm{sc}$ & - & ++ & +++ \\
\hline & & & $\mathrm{MD}$ & ++ & +++ & ++ & ++ & +++ \\
\hline & & & WD/MD & ++ & ++ & - & ++ & + \\
\hline & & & $\mathrm{MD}$ & + & ++ & + & + & + \\
\hline & & & $\mathrm{MD}$ & ++ & +++ & ++ & +++ & +++ \\
\hline & $\begin{array}{l}\text { Stage II* } \\
\left(\mathrm{T} 3 \mathrm{NxM}^{*}\right)\end{array}$ & 1 & MD & + & +++ & +++ & +++ & + \\
\hline & $\begin{array}{l}\text { Stage IV } \\
\text { (T3N1M1) }\end{array}$ & 1 & WD & +++ & +++ & +++ & +++ & +++ \\
\hline \multirow{2}{*}{$\begin{array}{l}\text { Overall } \\
\text { result }\end{array}$} & Normal & & & $0 / 3$ & $3 / 3$ & $0 / 3$ & $\mathbf{0} / \mathbf{3}$ & $\mathbf{0} / \mathbf{3}$ \\
\hline & PDAC & & & $21 / 21$ & $19 / 21$ & $13 / 19$ & $19 / 21$ & $16 / 19$ \\
\hline
\end{tabular}

For IHC: negative: -, sparse cells: sc; faintly positive (5-25\% stained cells): +; moderately positive $(25-60 \%$ stained cells): ++ ; and strongly positive ( $>60 \%$ stained cells): +++ .

For PLA: +++: positive cases whose median is higher than $75 \%$ of the overall median; ++: positive cases higher than $25 \%$ and lower than $75 \%$; and + positive cases lower than $25 \%$. 


\section{Figure Captions}

Figure 1: Expression of SLe ${ }^{x}$ and STn in PDAC. Immunohistochemistry staining of the SLe ${ }^{x}$ epitope at different magnification (x40 and $\mathrm{x} 200)$ and the corresponding hematoxylin eosin staining (x40) of normal pancreas (control) (A-C) and two representative pancreatic cancer tissues (well differentiated, D-F and poorly differentiated, G-I) with KM93 antibody. Immunohistochemistry staining of the STn antigen at different magnification (x40 and $\mathrm{x} 200)$ and the corresponding hematoxylin eosin staining (x40) of a control (J-L) and two representative pancreatic cancer tissues (well differentiated, M-O and poorly differentiated, P-R) with TKH2 antibody.

Figure 2: Expression of MUC1 and MUC5AC in PDAC. Immunohistochemistry staining at different magnification (x40 and $\mathrm{x} 200)$ and the corresponding hematoxylin eosin staining $(\mathrm{x} 40)$ of normal pancreas (control) (A-C), and two representative pancreatic cancer tissues (well differentiated, D-F and poorly differentiated G-I) with the anti-MUC1 antibody VU4H5. Immunohistochemistry staining of a control (J-L) and two representative pancreatic cancer tissues (well differentiated, M-O and poorly differentiated P-R) with the anti-MUC5AC antibody CLH2.

Figure 3: Expression of MUC1-SLe ${ }^{x}$ in PDAC. Expression of MUC1 (A and D) and SLe ${ }^{x}$ antigen (B and E) and their colocalization by in situ PLA in moderately differentiated (C) and poorly differentiated (F) PDAC tissues. x200 magnification.

Figure 4: Expression of MUC5AC-SLe ${ }^{\mathrm{x}}$ in PDAC. Expression of MUC5AC (A, D and G) and $\mathrm{SLe}^{\mathrm{x}}$ antigen $(\mathrm{B}, \mathrm{E}$ and $\mathrm{H})$ and their colocalization by in situ PLA in tumour ducts (C), mucus (F) and poorly differentiated tumour (I). x200 magnification.

Figure 5: Expression of MUC1-STn and MUC5AC-STn in PDAC. Expression of MUC1 (A) and MUC5AC (D) and STn antigen (B and E) and its corresponding colocalization by in situ PLA in pancreatic cancer tissues (C and F). x200 magnification.

Figure 6: A. MUC5AC and SLe ${ }^{x}$ western blots of pancreatic tissue lysates. Western blots corresponding to four control (C1-C4) and eight PDAC tissue lysates (T1-T8) with Lum5.1 antibody to detect MUC5AC (top panel) and KM93 to detect SLe ${ }^{\mathrm{x}}$ (bottom panel) are shown. B. Detection of SLe $^{x}$ on immunoprecipitated MUC5AC from a PDAC tissue lysate (T1). Representative Western blots with Lum5.1 antibody to detect MUC5AC (top panel) or with KM93 to detect SLe ${ }^{\mathrm{x}}$ (bottom 
panel) are shown. Lane 1: PDAC lysate. Lane 2: Immunoprecipitated (IP) PDAC lysate with Lum5.1 antibody. 

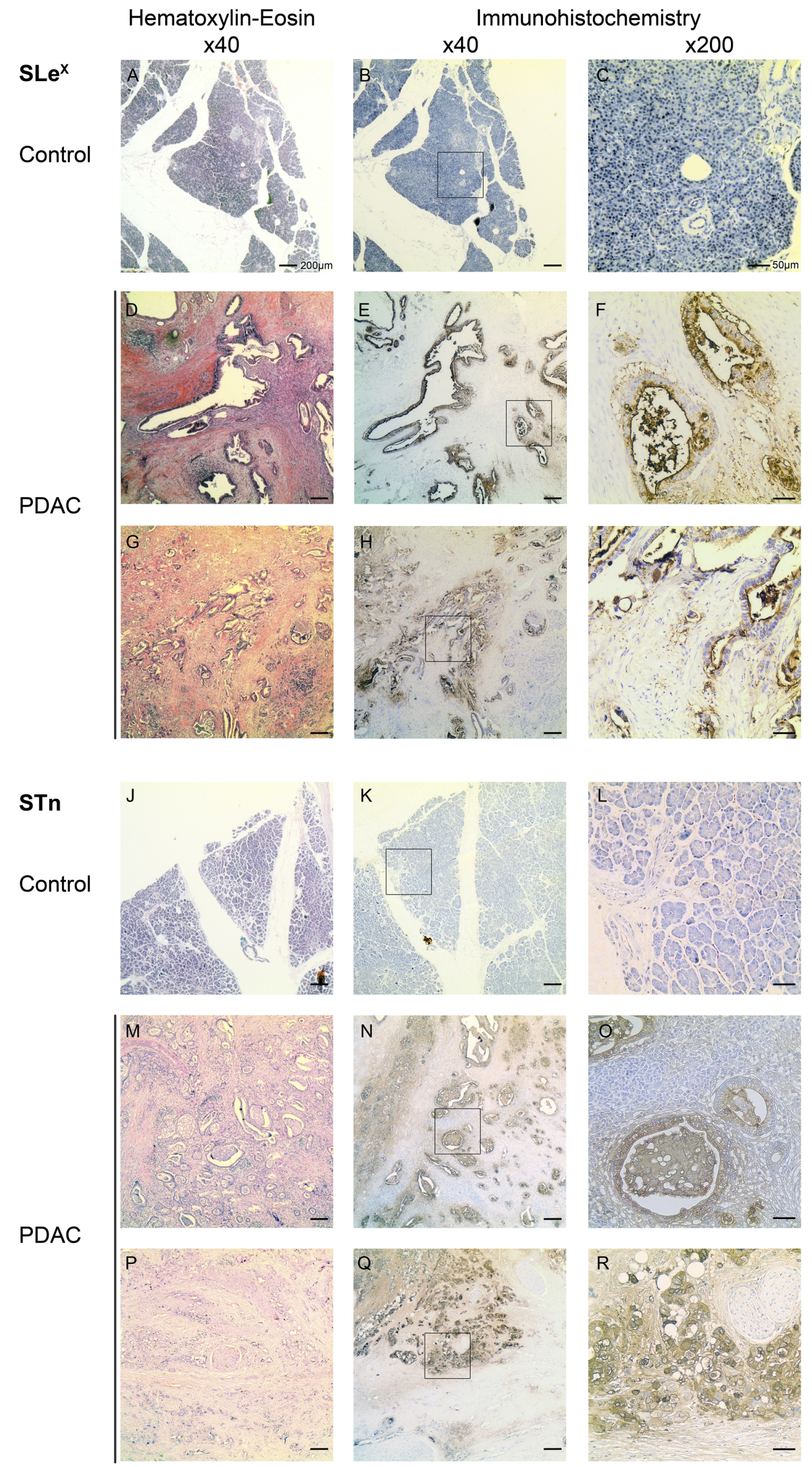
Hematoxylin-Eosin

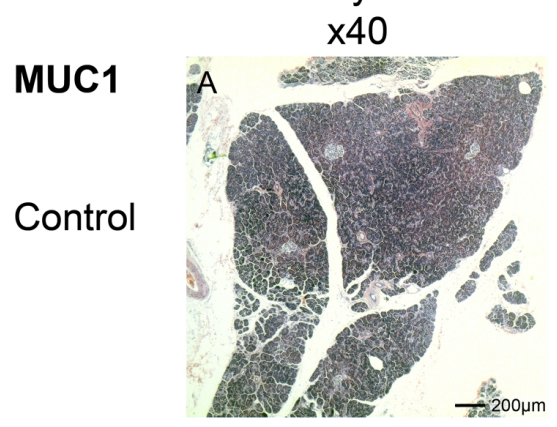

PDAC
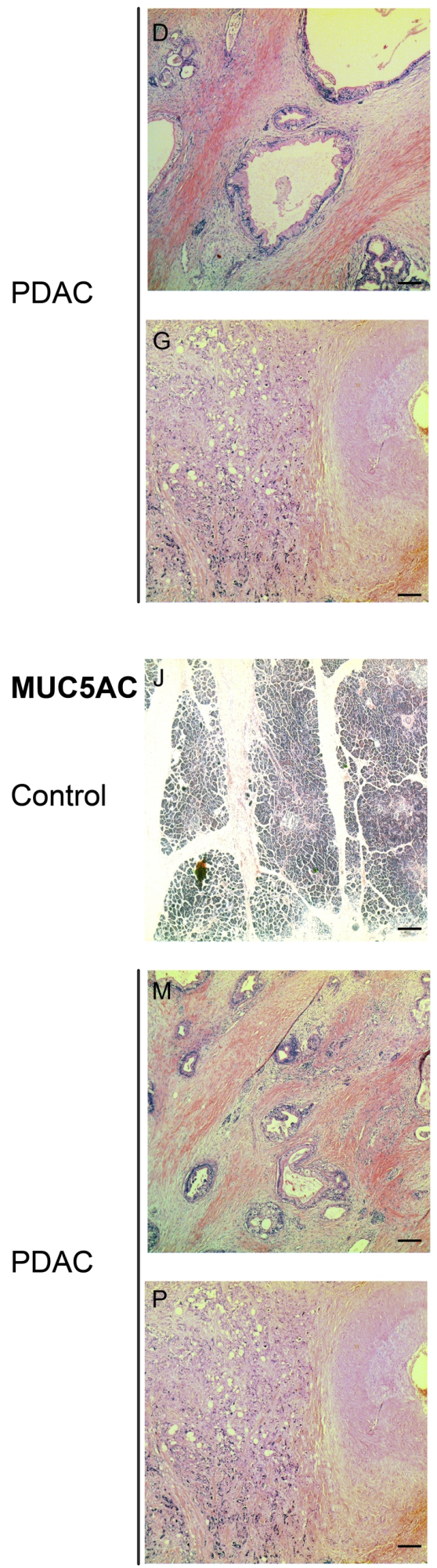
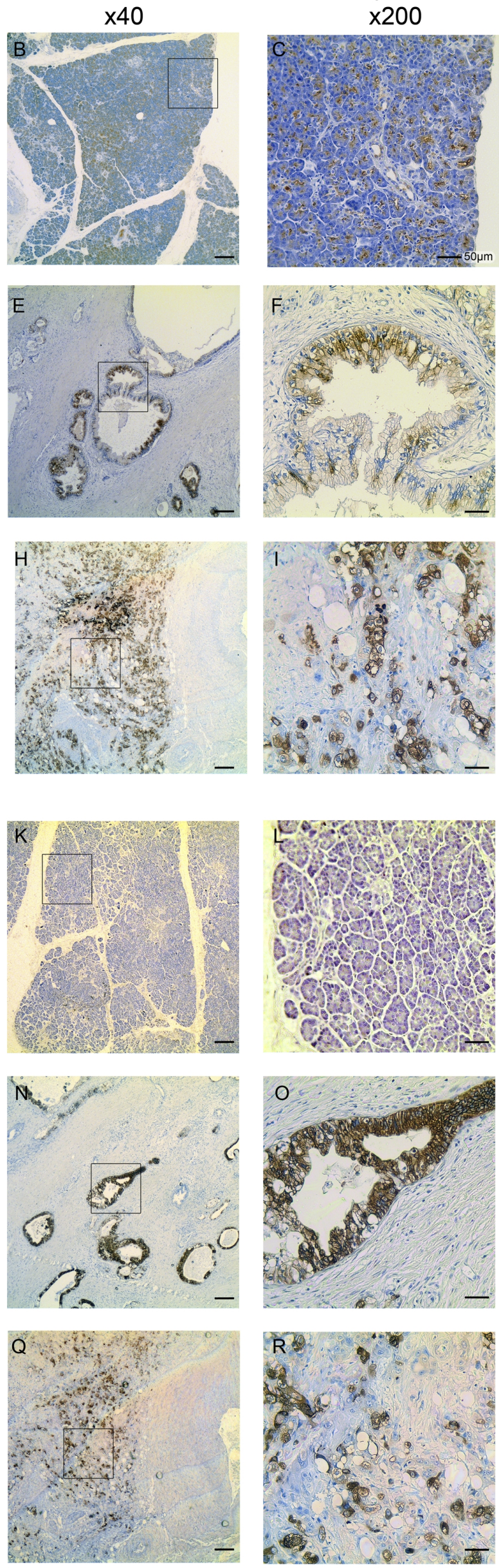
MUC1
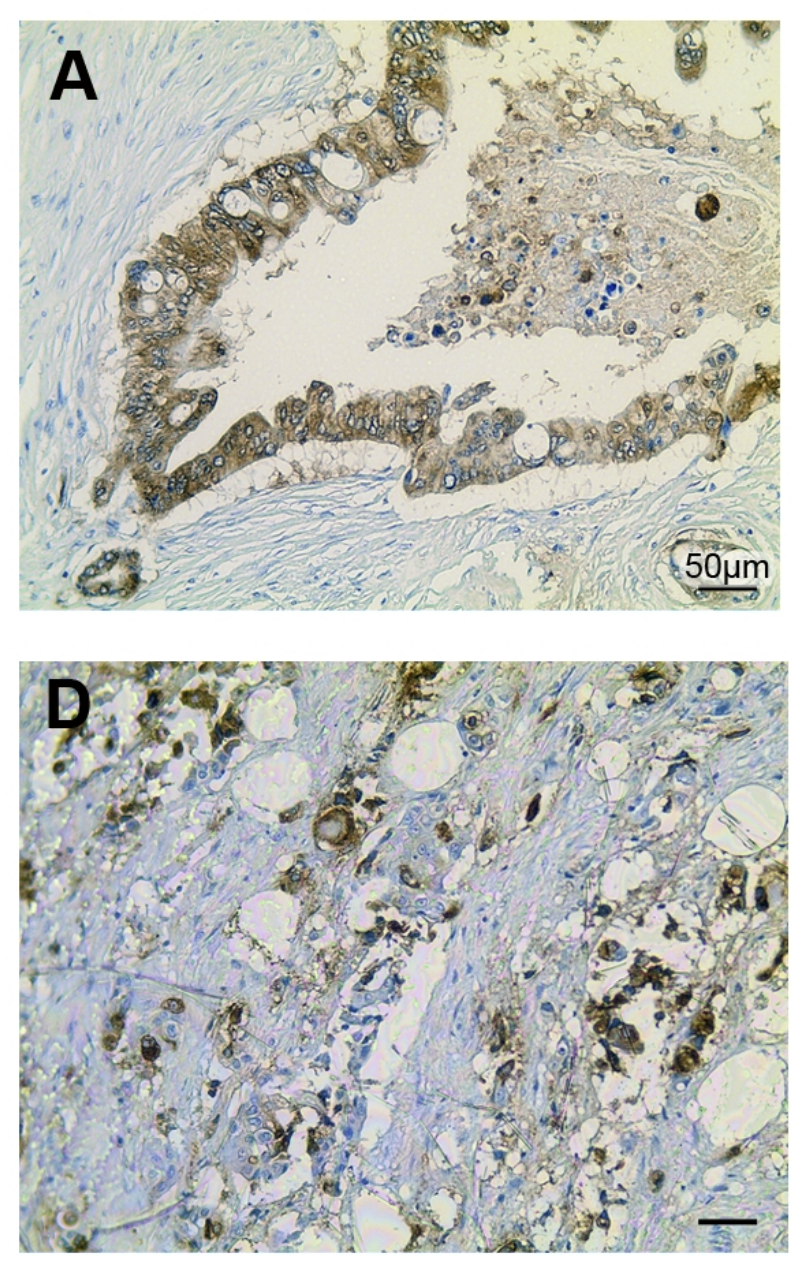

SLe ${ }^{x}$
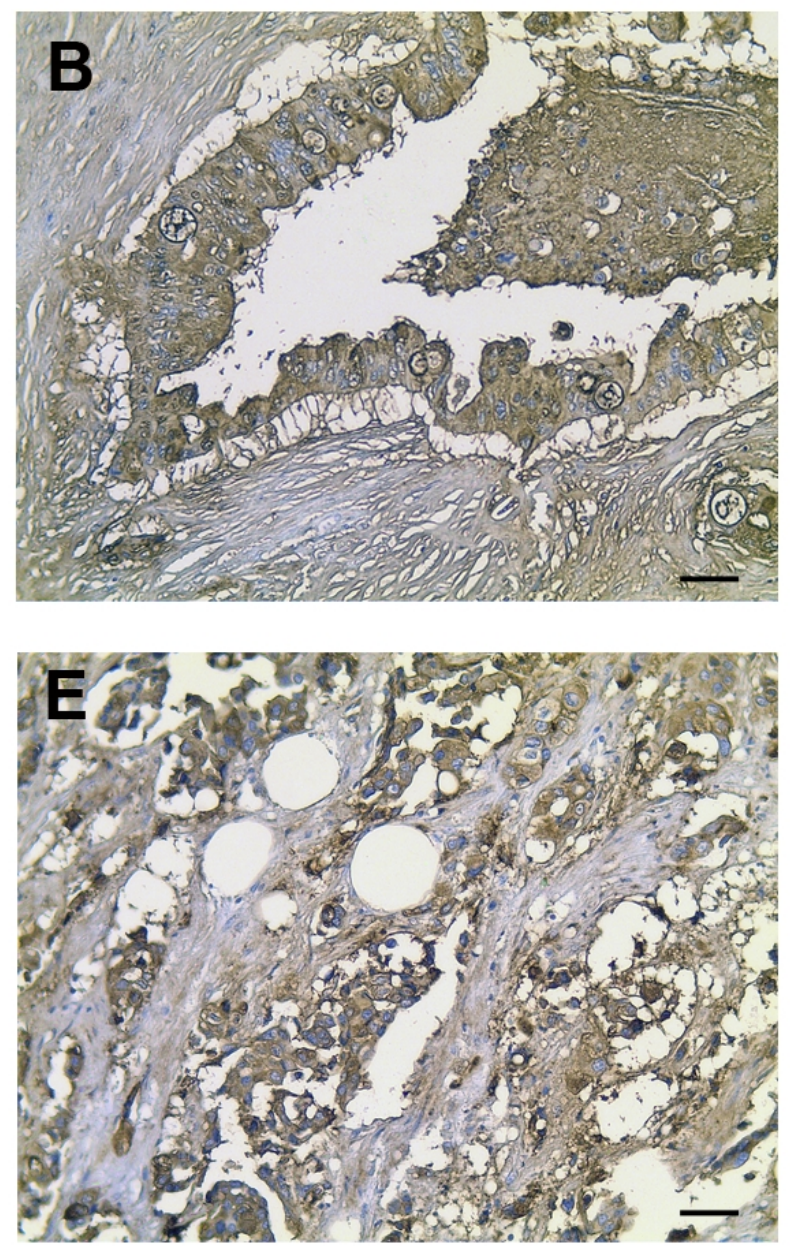

MUC1-SLe ${ }^{x}$
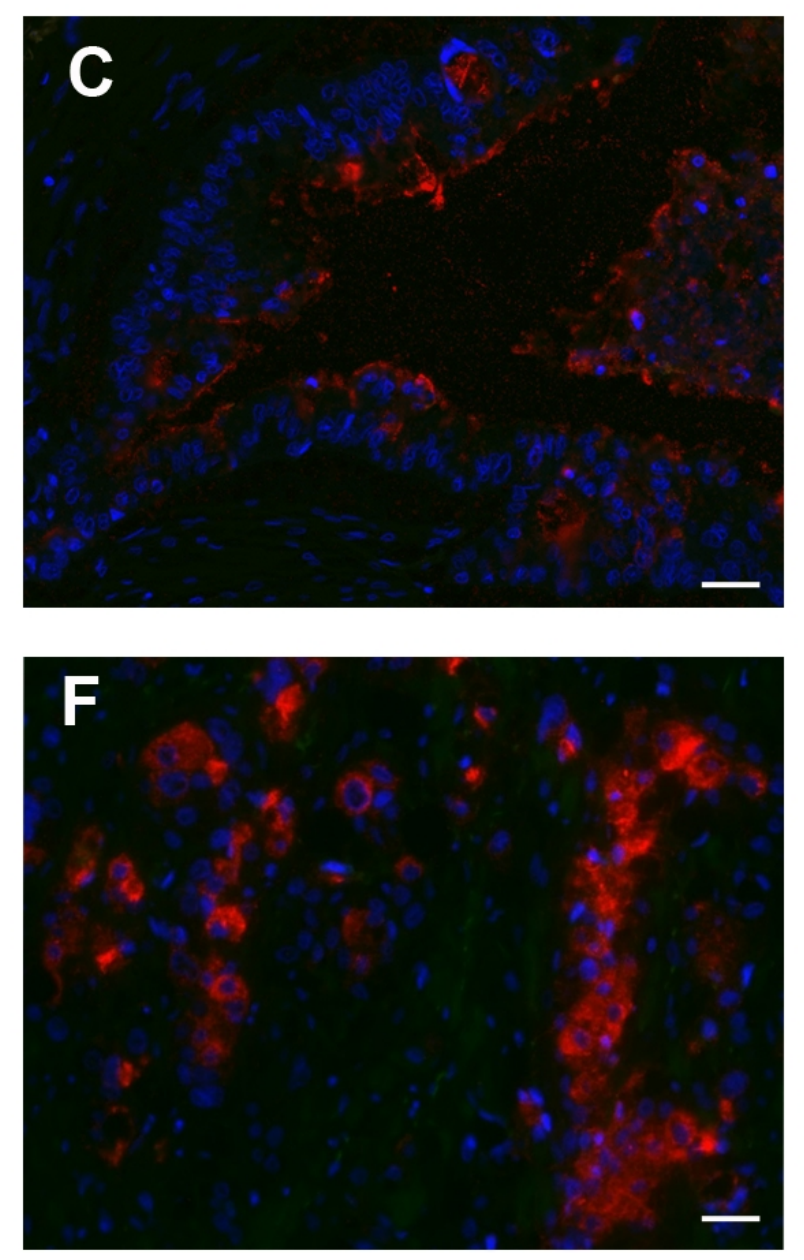
MUC5AC
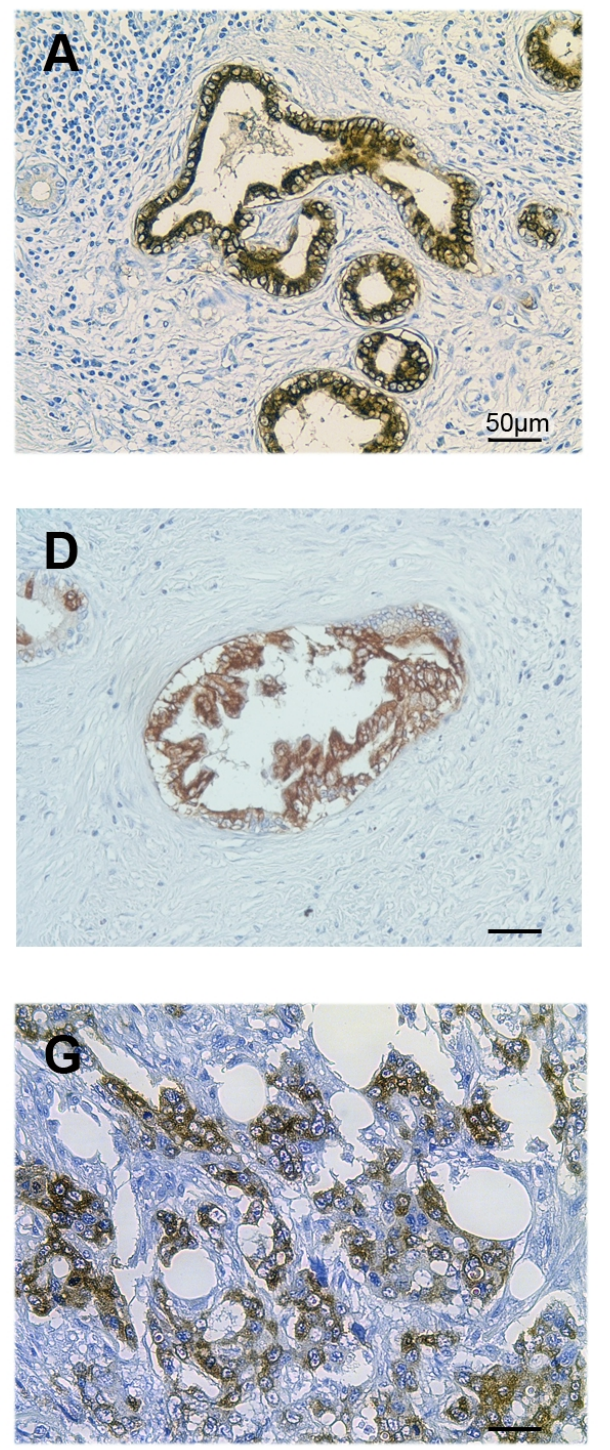

$S L e^{x}$

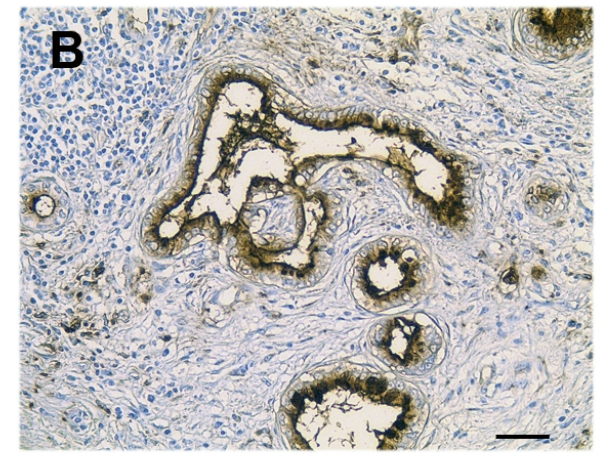

E)
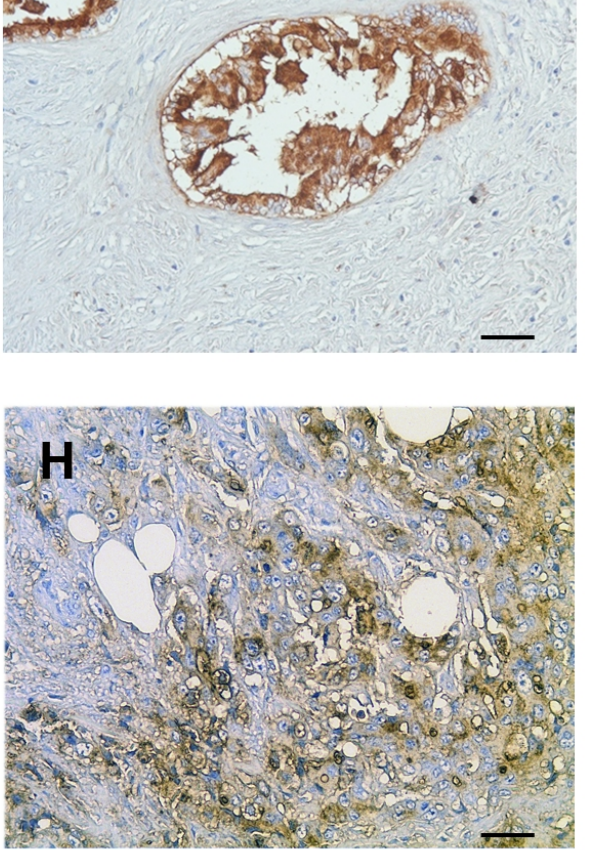

MUC5AC-SLe

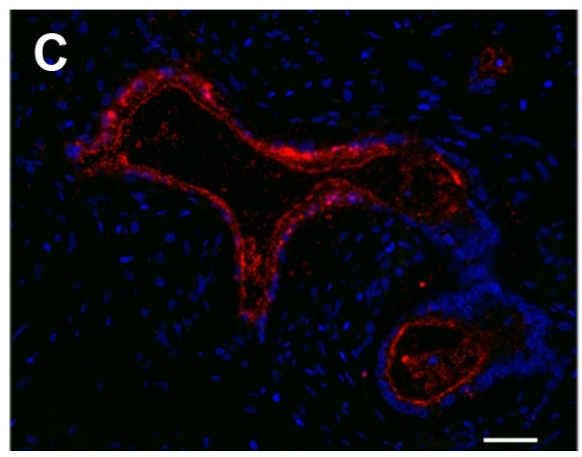

F
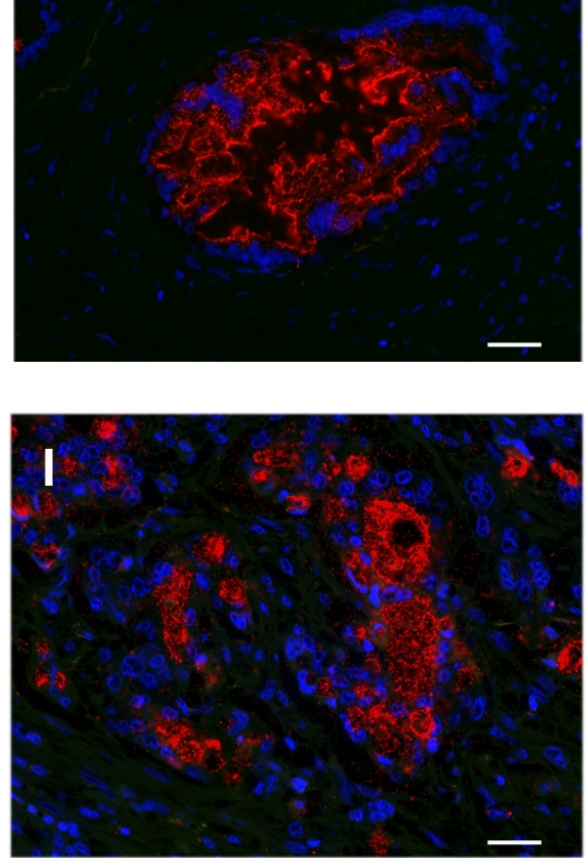
MUC1

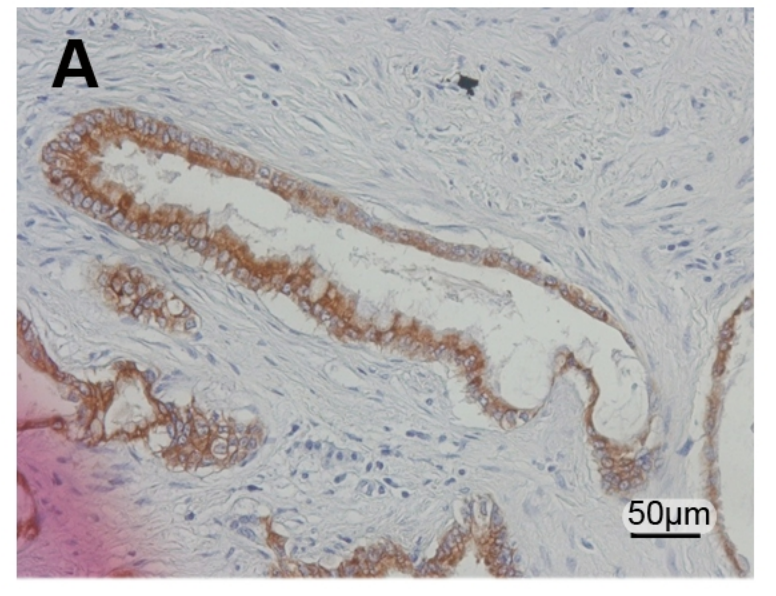

MUC5AC

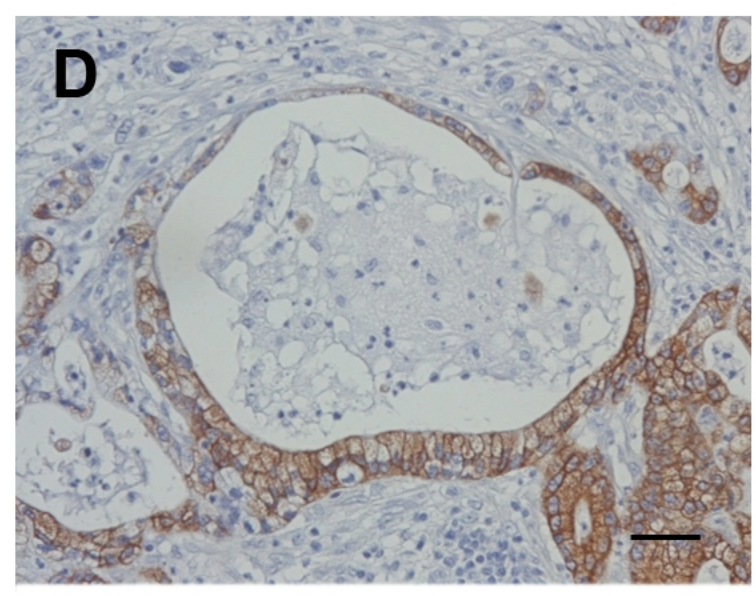

STn

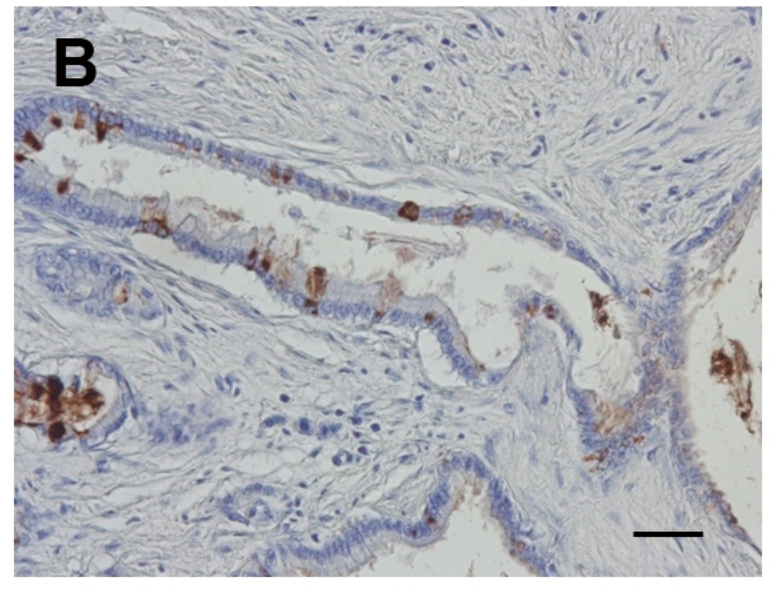

STn

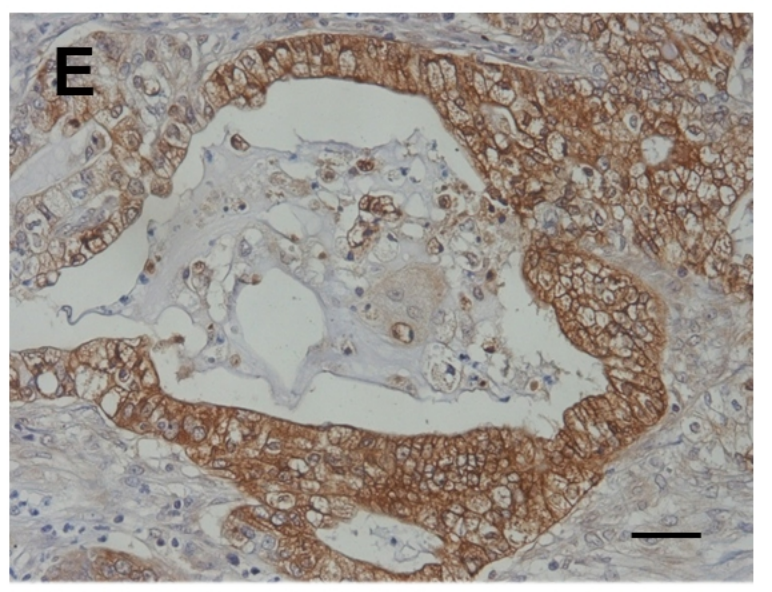

MUC1-STn

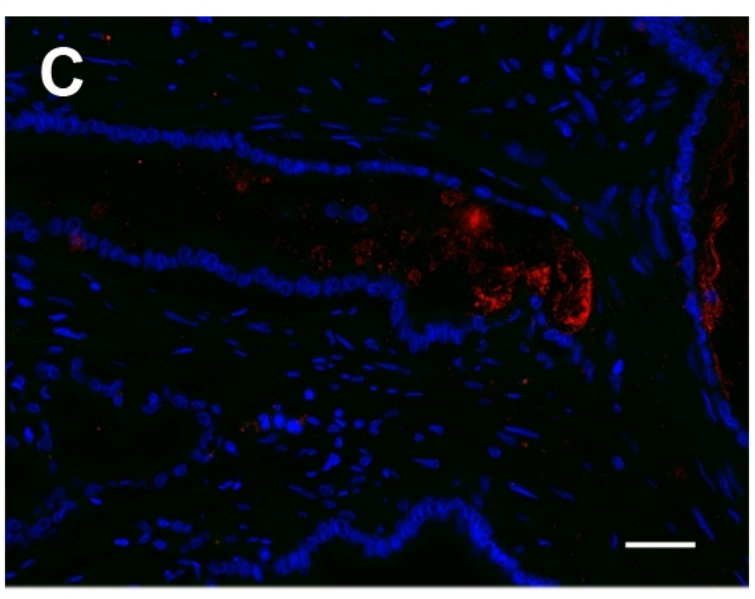

MUC5AC-STn

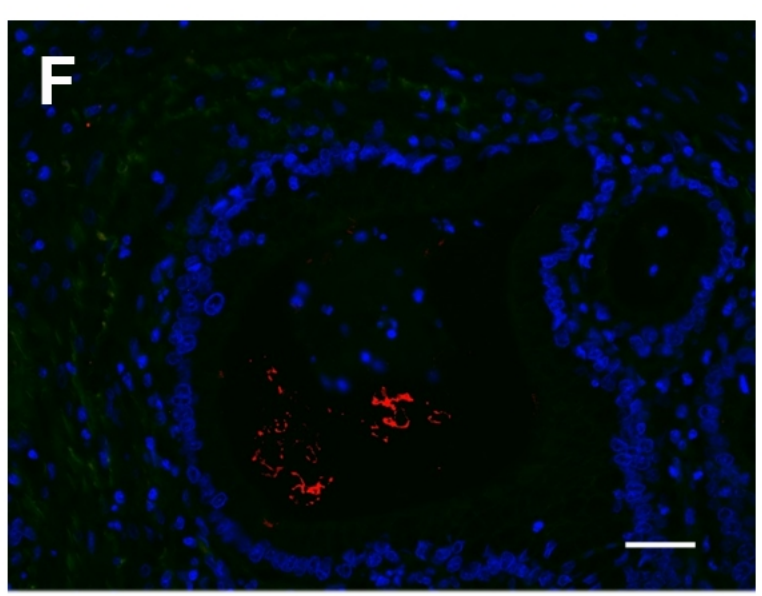


A

Control

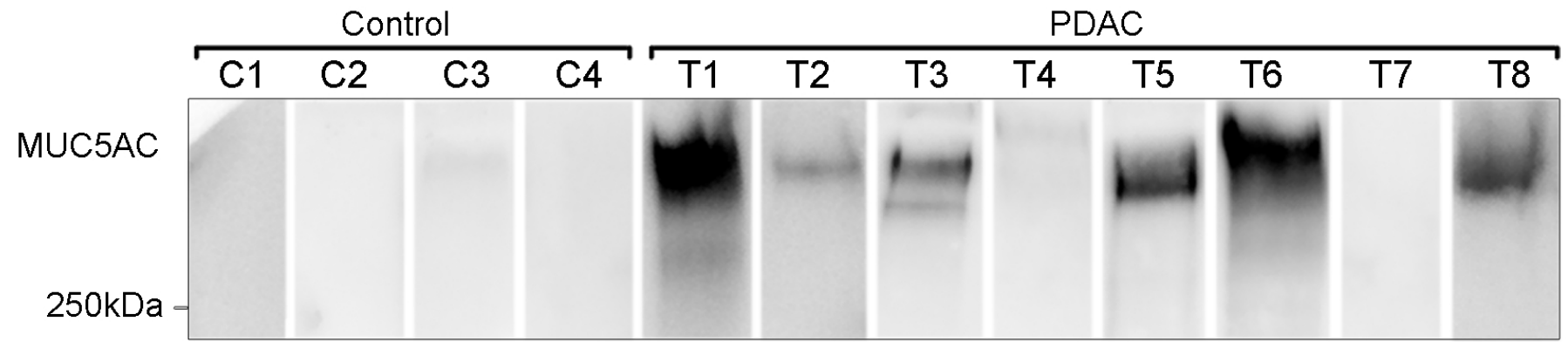

$S L e^{x}$

$250 \mathrm{kDa}$

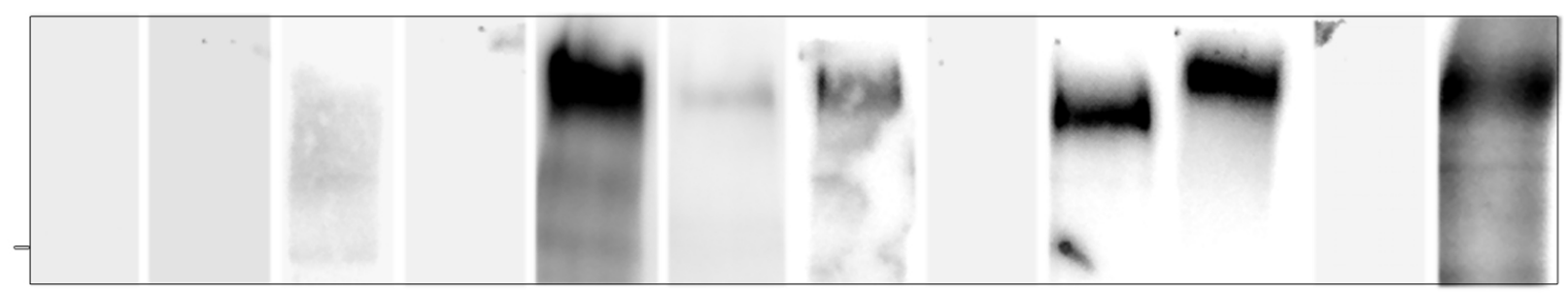

B

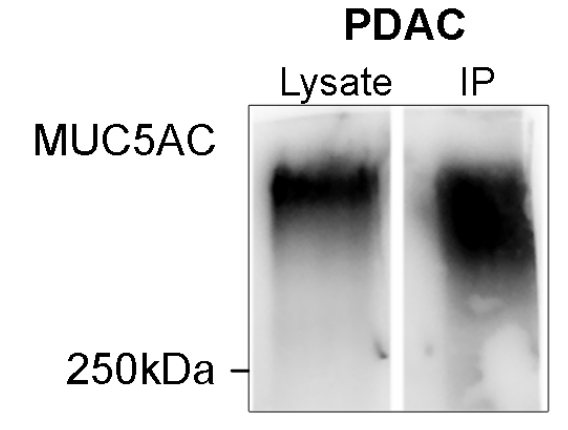

SLe

$250 \mathrm{kDa}-$ 

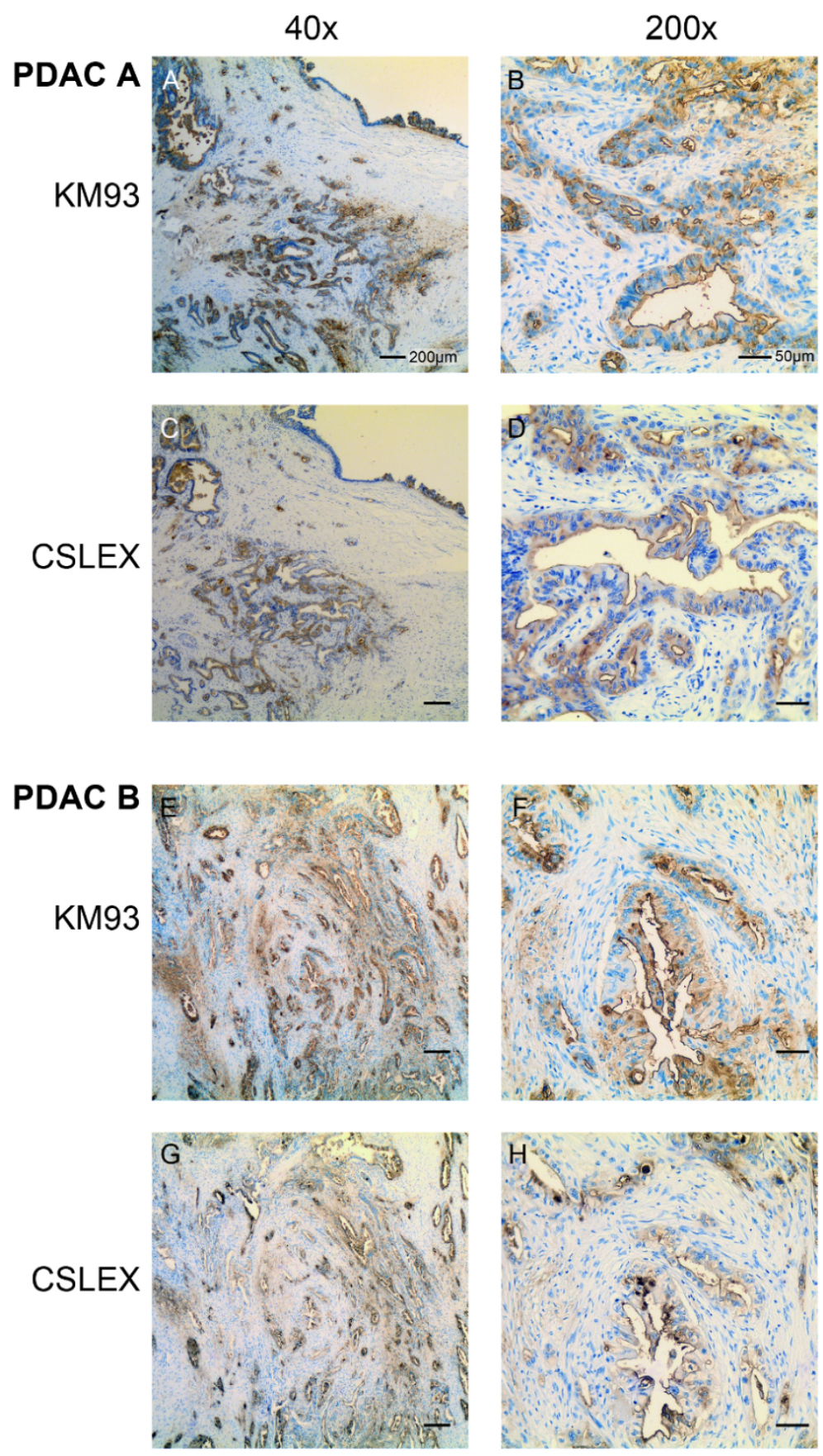

Figure S1. SLex staining pattern using KM93 and CSLEX antibodies.

Immunohistochemistry staining of the SLe ${ }^{\mathrm{x}}$ epitope at different magnification (x40 and $\left.\mathrm{x} 200\right)$ of two representative pancreatic adenocarcinoma tissues. A-D corresponds to a IIB, moderately differentiated PDAC (PDAC A) and E-H corresponds to a IIB, well differentiated PDAC (PDAC B) 


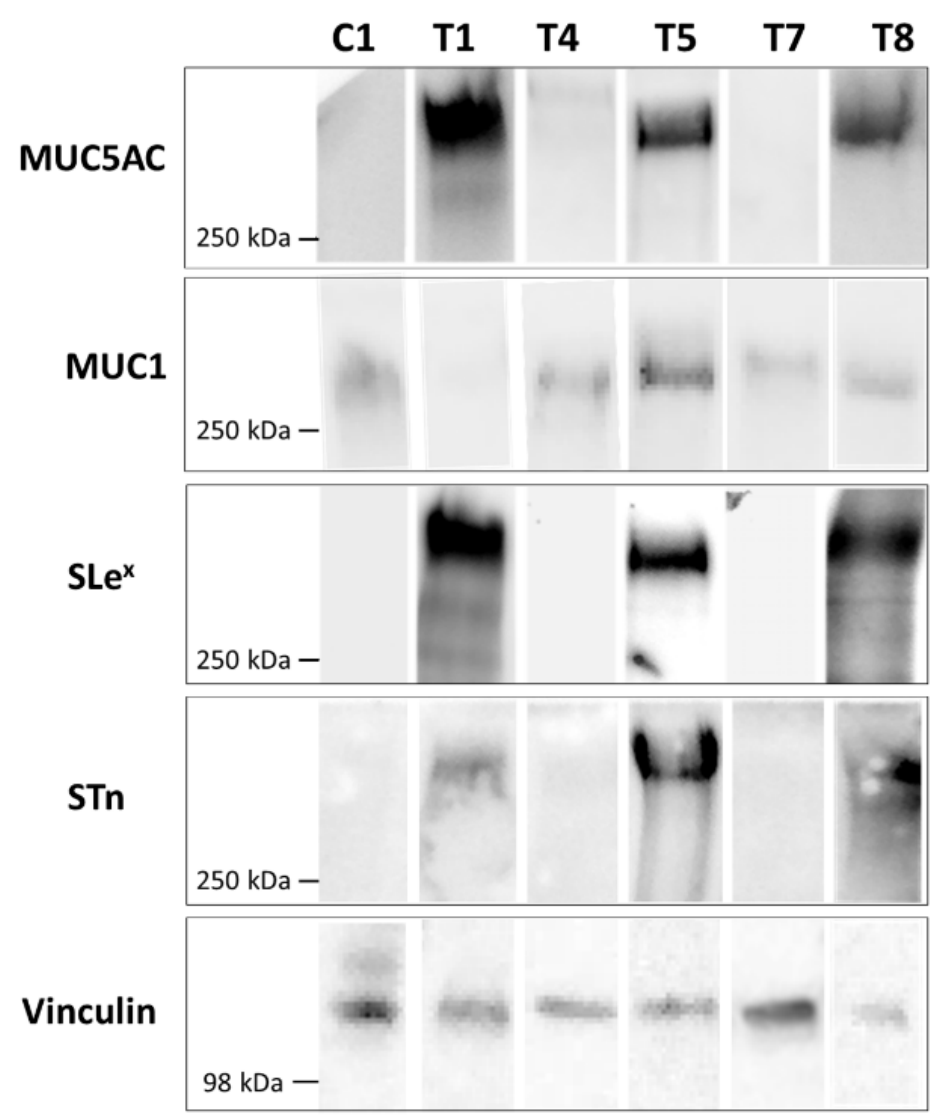

Figure S2: Expression pattern of MUC5AC, MUC1, SLe ${ }^{x}$, STn and vinculin in six of the the pancreatic tissue lysates. Western blots of $20 \mu \mathrm{g}$ of one control (C1) and of five PDAC tissue lysates (T1, T4, T5, T7, T8) to detect mucins (MUC5AC and MUC1), carbohydrate antigens (SLe ${ }^{\mathrm{x}}$ and $\left.\mathrm{STn}\right)$ and vinculin. 